\title{
THE RELATIONSHIP BETWEEN EGO-DEPLETION AND SENSORY PROCESSING SENSITIVITY
}

\author{
by \\ Karin Sobocko \\ A thesis submitted to \\ the Faculty of Graduate and Postdoctoral Affairs \\ in partial fulfillment of the requirements for the degree of \\ Master of Arts \\ in \\ Psychology
}

Carleton University

Ottawa, Canada

(C)2012 Karin Sobocko 
Library and Archives

Canada

Published Heritage

Branch

395 Wellington Street

Ottawa ON K1A ON4

Canada
Bibliothèque et

Archives Canada

Direction du

Patrimoine de l'édition

395 , rue Wellington

Ottawa ON K1A ON4

Canada
Your file Votre référence

ISBN: 978-0-494-93594-1

Our file Notre référence

ISBN: 978-0-494-93594-1
NOTICE:

The author has granted a nonexclusive license allowing Library and Archives Canada to reproduce, publish, archive, preserve, conserve, communicate to the public by telecommunication or on the Internet, loan, distrbute and sell theses worldwide, for commercial or noncommercial purposes, in microform, paper, electronic and/or any other formats.

The author retains copyright ownership and moral rights in this thesis. Neither the thesis nor substantial extracts from it may be printed or otherwise reproduced without the author's permission.
AVIS:

L'auteur a accordé une licence non exclusive permettant à la Bibliothèque et Archives Canada de reproduire, publier, archiver, sauvegarder, conserver, transmettre au public par télécommunication ou par l'Internet, prêter, distribuer et vendre des thèses partout dans le monde, à des fins commerciales ou autres, sur support microforme, papier, électronique et/ou autres formats.

L'auteur conserve la propriété du droit d'auteur et des droits moraux qui protege cette thèse. $\mathrm{Ni}$ la thèse ni des extraits substantiels de celle-ci ne doivent être imprimés ou autrement reproduits sans son autorisation.
In compliance with the Canadian Privacy Act some supporting forms may have been removed from this thesis.

While these forms may be included in the document page count, their removal does not represent any loss of content from the thesis.
Conformément à la loi canadienne sur la protection de la vie privée, quelques formulaires secondaires ont été enlevés de cette thèse.

Bien que ces formulaires aient inclus dans la pagination, il n'y aura aucun contenu manquant. 


\begin{abstract}
In 1997 Elaine Aron introduced the personality construct of high sensitivity, characterized by having an overactive sensory processing sensitivity that controls the way information is transmitted and processed in the brain. The primary purpose of this study was to assess whether continuous self-regulation among more sensitive people produces accelerated states of egodepletion, which in turn could explain their poor cognitive and social performance. Although the results indicated that sensitivity was not a significant moderating factor in the relation between noise and cognitive performance, the pattern of the findings was consistent with expectations. The secondary purpose of the study was to replicate Aron and Aron's (1997) findings, showing that sensory processing sensitivity is related to, yet distinct from, introversion and neuroticism, as well as to replicate the findings of Smolewska, McCabe, and Woody (2006) refuting the unidimentional character of the Highly Sensitive Person scale. Replications of both studies were successful.
\end{abstract}




\section{Table of Contents}

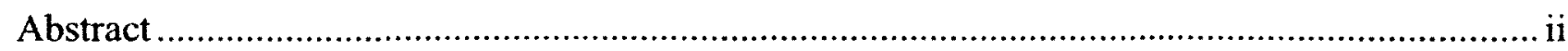

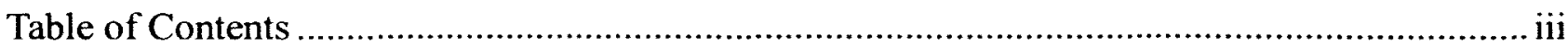

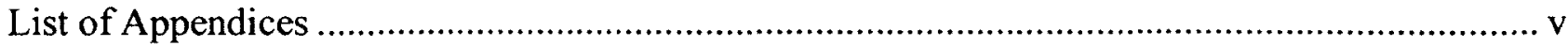

Sensory Processing Sensitivity and Highly Sensitive People .......................................... 2

Sensory Processing Sensitivity and Introversion .................................................... 3

The Highly Sensitive People Scale as a Three-Factor Construct....................................... 8

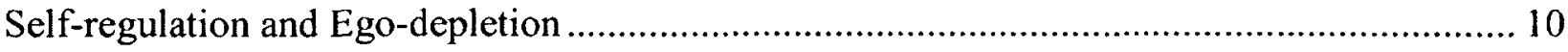

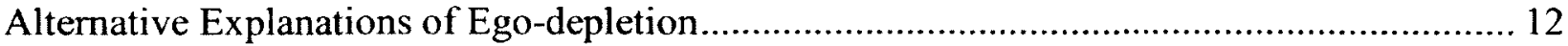

Self-regulation and Ego-depletion as Dispositional Constructs .................................... 14

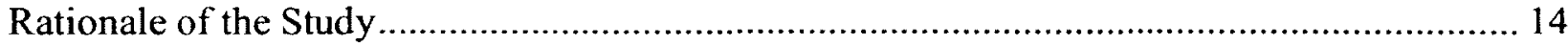

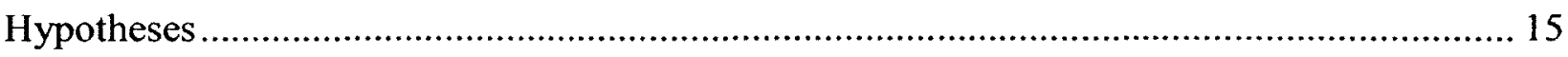

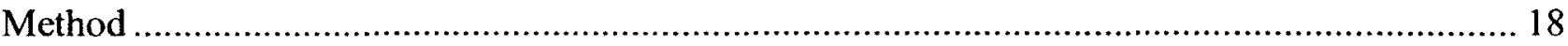

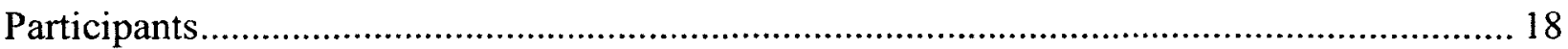

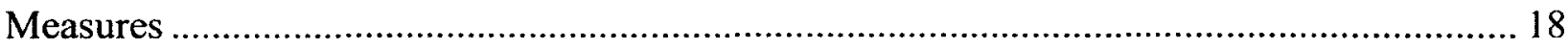

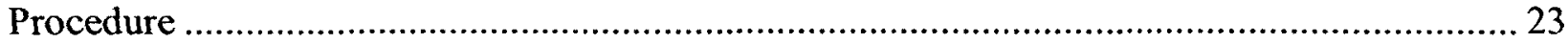

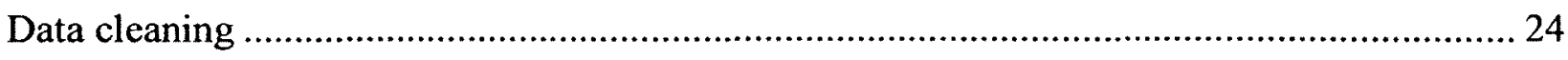

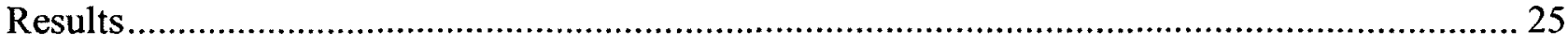

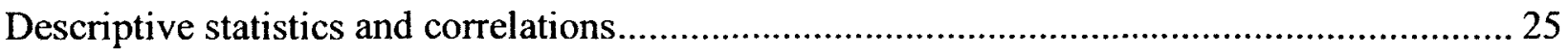

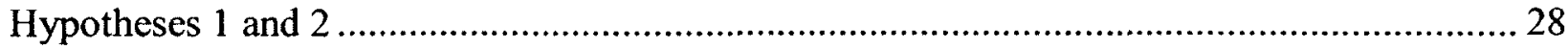

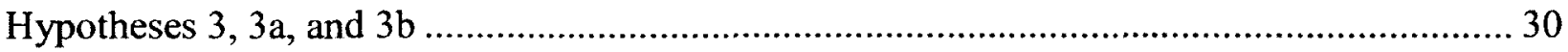

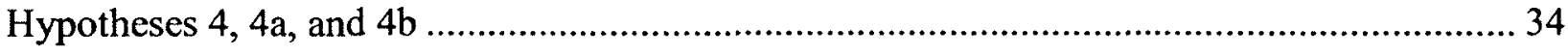

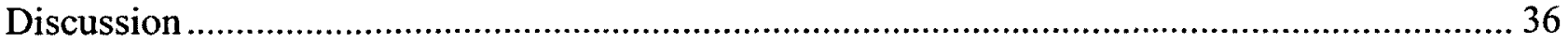




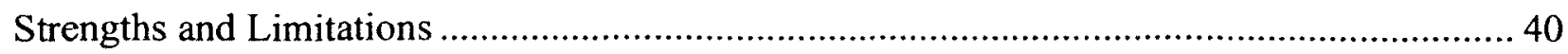

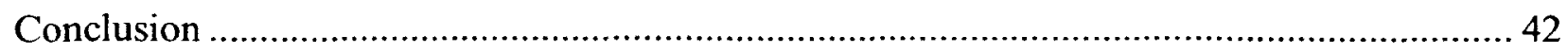

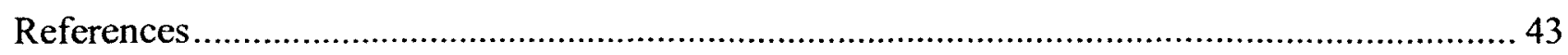




\section{List of Appendices}

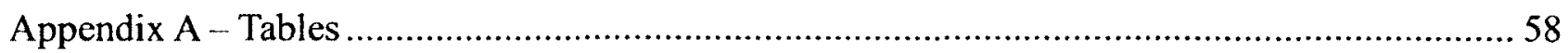

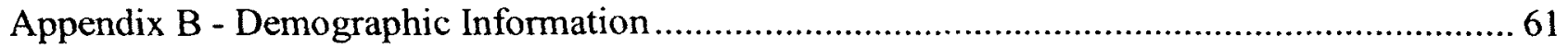

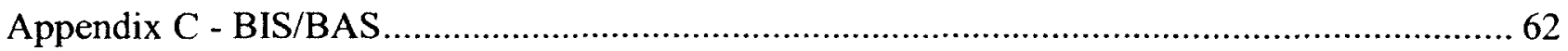

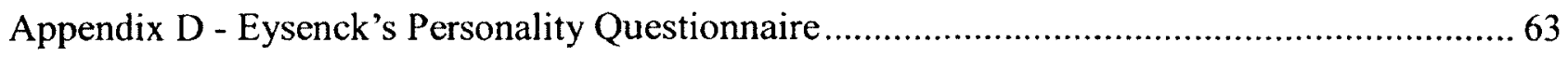

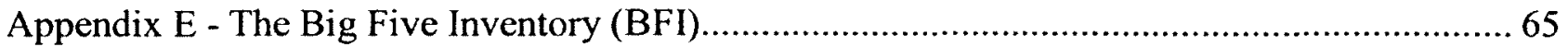

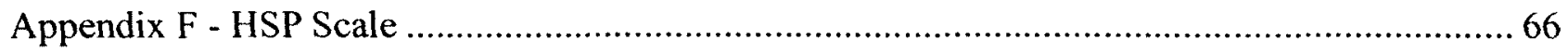

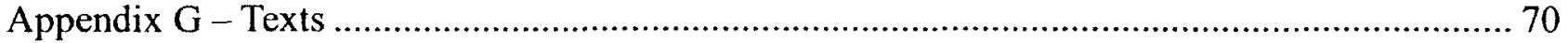

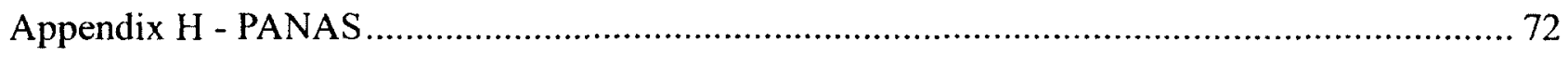

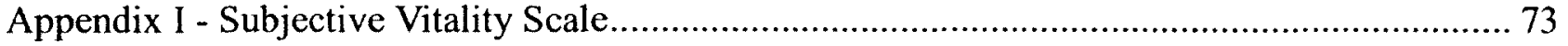

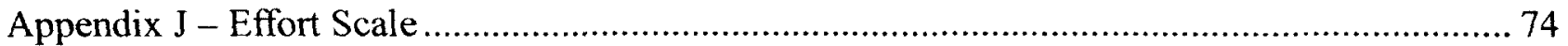




\section{Relationship between Ego-depletion and Sensory Processing Sensitivity}

There are multiple ways people experience and respond to their surroundings.

Environmental inputs trigger the same senses in human beings, but the resulting sensations and their strengths differ for everyone. There has been limited research in trying to understand the challenges faced by people with high sensitivity. In 1997, Aron and Aron addressed this issue by introducing the notion of highly sensitive people, people whose sensitivity to environmental stimuli is strong enough to interfere with their daily lives. Since then, most of the studies published about highly sensitive people point to a similar outcome of the high sensitivity - the highly sensitive people's social, academic, and work performance is worse than that of less sensitive people (Aron and Aron, 1997; Evers, Rasche, \& Schabracq, 2008; Liss, Mailloux, \& Erchull, 2008). One possible reason for this under-performance of highly sensitive people is the notion that being extra vigilant of everything happening around them makes them more prone to being over-aroused and overwhelmed. Therefore, in order for them to function normally in society, they need to control their responses to various stimuli. However, this does not come without a price. Humans have a limited amount of energy, and constant self-control could accelerate its depletion, which, in turn, could diminish their cognitive abilities (Baumeister \& Vohs, 2007). The main goal of this study was, therefore, to assess whether the constant selfcontrol, and the resulting acceleration of ego-depletion, could constitute a possible, previously unexplored, explanation for the highly sensitive people's cognitive and social under-performance. In addition, this study tried to replicate Aron and Aron's (1997) findings that being a highly sensitive person is related to, but distinct from, being an introvert. 


\section{Sensory Processing Sensitivity and Highly Sensitive People}

Among all humans and animals, two strategies of dealing with environmental changes have been identified: an approach and exploration of a new stimulus; or vigilance, assessment, and often avoidance of it (Aron \& Aron, 1997; Smolewska, McCabe, \& Woody, 2006). Aron and Aron (1997) proposed that the choice of a strategy used to deal with a new stimulus depends on a person's sensory processing sensitivity (SPS) - the way in which sensory information is transmitted to and processed in the brain. Based on their qualitative interviews and quantitative studies, Aron and Aron (1997) concluded that between 15\% and 20\% of the general population consists of people with a highly active sensory processing sensitivity; they defined such people as highly sensitive, i.e. people easily overaroused and overwhelmed by a variety of sensory inputs, e.g. strong smells, loud noises, bright light, or strong tastes. Such highly sensitive people (HSP) engage in a deep processing of new information before taking any action, which gives them enough time to notice all the subtleties of the stimulus (Aron, 2004). The high innate sensitivity and hyperawareness of social cues lead to the highly sensitive people's increased autonomic arousal in situations with intense or prolonged sensory inputs. Situations moderately arousing for the general population, such as places with loud music, being around strong smells, or touching coarse fabrics, can all easily overwhelm a highly sensitive person. Aron and Aron (1997) hypothesized that being in arousing situations, and being so easily aroused and overwhelmed, are reasons why highly sensitive people are considered to exhibit poor coherence manageability, meaningfulness, have lower self-efficiency and higher levels of alienation (Evers, Rasche, \& Schabracq, 2008) - all of which could potentially have a detrimental effects on their academic, social, or work performances. However, when being alone or in a peaceful environment, their efficiency increases, as they are able to take advantage of their sensitivities. 
Highly sensitive people excel in understanding, appreciation, and creation of culinary, musical, and visual arts (Aron, 1996).

\section{Sensory Processing Sensitivity and Introversion}

While operationalizing their concept of the highly sensitive person, Aron and Aron (1997) suggested that sensitivity was often confused with other personality traits. They pointed out that when people are more vigilant in face of a new situation, it often results in them being labelled as neurotic (Howarth, 1986), inhibited (Kagan, 1994), fearful (Buss \& Plomin, 1984; Gray, 1991), or introverted. In fact, various studies showed that introverts have a greater sensitivity than others. Introverts were found to be more sensitive to low auditory frequencies (Stelmack \& Campbell, 1974; Stelmack \& Michaud-Achorn, 1985), pain (Barnes, 1975; Schalling, 1971), electrocutaneous thresholds (Edman, Schalling, \& Rissler, 1979), olfactory thresholds (Herbener, Kagan, \& Cohen, 1989), and to visual thresholds (Siddle, Morrish, White, \& Mangan, 1969).

Furthermore, a significant connection between sensitivity and introversion was also found by Jerome Kagan. He successfully predicted that four-month old infants, classified by him as "high-reactive" after exposing them to new experiences, would have a higher chance to develop into more inhibited, quiet, careful, and introverted teenagers. On the other hand, "low-reactive" infants had a higher chance to grow up into less inhibited, more relaxed, confident, and extraverted people. Kagan hypothesized that babies' physiological reactions were controlled by their amygdala. Babies with more excitable amygdalae would have a stronger reaction to unknown stimuli - higher blood pressure, higher levels of cortisol, and dilated pupils - since their amygdalae would perceive those stimuli as threatening. Therefore, he hypothesized and showed that, as long as environment and biology collaborate, being born with a sensitive nervous system, and therefore having an excitable temperament, is one of the routes to develop an 
introverted personality (Cain, 2012; Kagan \& Snidman, 2004).

Aron and Aron (1997) used Eysenck's (1967) model, similar to Kagan's work, as a theoretical tool to explain the connection between sensitivity and introversion. According to Eysenck's taxonomy, on top of the hierarchy stand superfactors, stable personality traits of psychoticism, extraversion, and neuroticism, which further consist of lower-order factors (more specific traits, e.g. negative affect). Furthermore, these lower-order traits are built of even lowerorder habits, which in turn are comprised of specific behaviours. All together, they created four quadrants, which are said to define four temperaments of: stable extraverts (sanguine temperament: outgoing, talkative, responsive, easygoing, lively), unstable extraverts (choleric temperament: touchy, restless, excitable, changeable), stable introverts (phlegmatic temperament: calm, even-tempered, reliable, controlled, careful, passive), and unstable introverts (melancholic temperament: quiet, reserved, pessimistic, rigid, anxious; Eysenck \& Eysenck, 1985).

Observed by Aron and Aron (1997), weak, positive correlations between high sensitivity and introversion, as well as high sensitivity and neuroticism, were interpreted by them as indicative of distinctions between those personality dimensions. Thus, considering above correlations, which show a connection between introversion, neuroticism, and high sensitivity, yet denote distinctiveness of these personality traits, it seems plausible that high sensitivity is one of the lower-order factors contained within the superfactors of introversion and neuroticism.

Eysenck saw introverts as having a more active ascending reticular activating system (ARAS) - a structure in the brain stem, which was thought to control overall cortical arousal by controlling the amount of nervous stimulation entering the cortex. According to Eysenck's theory, introverts have higher resting level of arousal because their ARAS allows a significant amount of stimulation to reach their cortices, which results in them being more easily 
overaroused during habituation to a new stimulus.

Eysenck (1994) defined habituation as a result of an increased stimulation, which increases central nervous system reactivity until the moment of reaching an optimal point, after which starts the process of inhibition. In other words, habituation happens as a person gets used to a new stimulus or gets bored due to repeated exposure to that stimulus. Eysenck (1994) stated that when introverts are presented with a new stimulus, it absorbs most of their attention. They are slower in habituation to that new stimulus, and while they are getting accustomed to it, they are likely to avoid other new stimuli; consequently, they are likely to avoid places and situations with high levels of arousal. On the other hand, inhibition happens much faster for extraverts, which makes them more likely to look for stimulation in order to avoid boredom.

Since its formulation, a few problems were noticed and addressed within Eysenck's model. The major critique comes from studies which showed that it is not baseline arousal levels that differentiate introverts and extraverts, but rather their different arousability. Specifically, Stelmack (1990) and Gale's (1987) studies indicated that extraverts and introverts' brain activity levels were the same while sleeping, but during a moderate level of stimulation, introverts had more enhanced physiological reactivity than extraverts. Furthermore, it has been also suggested that introverts are not necessarily absorbed by the new stimulus to the point that there is no place for any extra processing to happen without overwhelming them. In fact, it is possible that the state of overarousal brought by new stimuli makes everything in the environment more, not less, unpleasantly noticeable and this is why such people prefer to withdraw to quieter places (Aron \& Aron, 1997). Also, it was pointed out that introverts are not always aroused to the point that a small amount of an extra stimulation could cause their overarousal. In fact, studies showed that given a difficult task to perform, introverts did not become overwhelmed faster by it, and did not 
perform worse than when given a simple problem to solve (Harley \& Matthews, 1992; Shigehisa, 1974). Therefore, although Eysenck's model was not an ideal one, its main idea that introversion is a result of a predisposition to a higher arousability seems parallel to an excessive arousability experienced by highly sensitive people.

Gray (1991) introduced and defined the behavioural activation system (BAS) and the behavioural inhibition system (BIS) as two brain systems responsible for most fundamental personality traits. The behavioural activation system is said to consist of the cortico-striatopallido-thalamic loops and pathways sensitive to catecholaminergic action, especially sensitive to dopamine action (De Pascalis, Fiore, \& Sparita, 1996). The BAS is a source of goal-directed behaviour, positive feelings, and responses to conditioned and unconditioned cues of reward (Corr, 2002). As such, people with more active BAS are seen as more impulsive, since they have problems with inhibition of their responses (Gray, 1991). On the other hand, the behavioural inhibition system (BIS) consists of the septohippocampal system, its monoaminergic afferents from the brain stem, and its neocortical projection in the frontal lobe. It is sensitive to punishment, novelty, non-reward, and it is especially active in people who exhibit increased anxiety levels (Gray, 1991).

Aron and Aron (1997) used reinforcement sensitivity theory (Gray, 1972, 1991) as a possible physiological explanation to connect sensitivity and the traits of introversion and neuroticism. They saw the true cause of HSP's sensitivity and avoidance behaviours as lying within the sensory processing sensitivity, which in turn is rooted in and defined by variations in the sensitivity of the behavioural activation and inhibition systems (Carver \& White, 1994; Gray, 1991).

Gray's model of anxiety and impulsivity is considered an alternative rotation in the 
Eysenck's extraversion and neuroticism conceptual space. Although, the debate about the specific position of Gray's dimensions in relation to Eysenck's dimensions is still active, it is widely accepted that the dimensions of anxiety and impulsivity lay at a 30 degree rotation to Eysenck's dimensions of neuroticism and extraversion (Matthews \& Gilliland, 1999). Specifically, those who are highly impulsive, those with the most active BAS, are seen as highly extraverted and only a bit neurotic, while those who are the least impulsive are seen as introverted and perhaps somewhat emotionally stable. Furthermore, the most anxious people, people with the most active BIS, are seen as highly neurotic and a bit introverted, while those who are extraverted and emotionally stable are considered the least anxious (Fowles, 2006).

Aron and Aron (1997) focused on the behavioural inhibition system, which they saw as a neuropsychological base of highly sensitive people's personality. Specifically, they proposed that a highly sensitive person is characterized by the high sensory processing sensitivity, which in turn is a result of an increased behavioural inhibition system's functioning. Furthermore, they saw the central task of the BIS as explaining its connection to the high sensitivity. Specifically, in the face of a threat, uncertainty, non-rewarding or punishing environment, the main task of the BIS is to briefly inhibit all actions, as well as to increase person's arousal and attention (Gray, 1991). During this brief moment, a person engages in a checking mode, during which the threatening stimulus is compared with an expected one, and a decision is made about the appropriate action. If during a checking mode a mismatch is detected between an experienced and an expected stimulus, the inhibition of approach behaviour becomes a permanent one. Aron and Aron (1997) suggested that among people with more active BIS, the constant heightened arousal possibly leads to the decline of the BIS's efficiency in the long run, since a person becomes more and more hypervigilant to all types of stimuli, not only the new or threating ones. 
People with more active BIS are, therefore, more easily distracted and less focused. They are overly sensitive to negative stimuli and as such they tend to anticipate danger unnecessarily (Gray, 1991). The tendency toward being overwhelmed by even a small level of stimulation among people with active BIS is what Aron and Aron's (1997) offered as a support for their notion, that having a high sensitivity is rooted in having a high BIS functioning.

Since high sensitivity could be seen as a result of a highly active BIS, and since, as previously mentioned, the BIS is especially active in highly neurotic people (Gray, 1991; Fowles, 2006), it would logically follow that being a highly sensitive person is similar to being a highly neurotic and a bit introverted person. In the course of their seven studies, Aron and Aron's (1997) concentrated on assessing whether high sensitivity is associated with a trait of introversion. They pointed out that standard measures of social introversion are weakly or moderately correlated with the Highly Sensitive People Scale: the Meyers-Briggs Type Indicator - Introversion/Extraversion $(r=0.14, p<0.10 ;$ Meyers, 1962), the Eysenck Personality Inventory - Extraversion Scale $(r=0.29, p<0.01$; Eysenck \& Eysenck, 1968), and the Big Five Inventory - Neuroticism $(r=0.41, p<0.05)$ and Extraversion/Surgency scales $(r=0.12, n s$; Goldberg, 1990). Therefore, they concluded that high sensitivity is related to, but distinct from, social introversion or negative emotionality.

\section{The Highly Sensitive People Scale as a Three-Factor Construct}

In 1997 Aron and Aron created the 27-item Highly Sensitive People scale (HSPS). The HSPS consists of a variety of items related to sensitivity, such as: "Are you easily overwhelmed by strong sensory input" or "Do you tend to be more sensitive to pain?". Aron and Aron (1997) considered the HSPS as a unidimensional measure of sensory processing sensitivity and reported that the scale reached adequate content, convergent, and discriminant validities, as well as a good 
reliability coefficient $(\alpha=0.87)$.

However, the major problem with the scale results from its inability to differentiate between different types of sensitivities. Therefore, after conducting a factor analysis, Smolewska, McCabe, and Woody (2006) proposed a division of the Highly Sensitive People scale into a three separate subscales, consisting of: the Ease of Excitation, the Aesthetic Sensitivity, and the Low Sensory Threshold subscales. The Ease of Excitation Subscale includes 12 items related to becoming mentally overwhelmed by external ("Do you find it unpleasant to have a lot going on at once?") or internal stimuli ("Does being hungry creates a strong reaction in you, disrupting your concentration or mood?"). The Aesthetic Sensitivity Subscale included seven items related to being aware of aesthetic stimuli ("Are you deeply moved by arts and music?"), while the Low Sensory Threshold Subscale consisted of six questions about feeling unpleasant arousal in face of external stimuli ("Are you easily overwhelmed by things like bright lights, strong smells, coarse fabrics, or sirens close by?"; Smolewska, et al., 2006).

The main reason for the popularity of the three-factor structure is the fact that the three types of sensitivities, which are assessed by those three subscales, correlate differently with other measures of personality traits. In fact, Smolewska et al. (2006) found that Gray's (1991) behavioural inhibition system (as assessed by Carver \& White's [1994] scale) is strongly associated with the Ease of Excitation subscale, but it shows much weaker association with the Aesthetic Sensitivity and the Low Sensory Threshold subscales. On the other hand, only the Reward Responsiveness subscale of the behavioural activation system has been shown to have a small association with the Ease of Excitation and the Aesthetic Sensitivity subscales (Smolewska at al., 2006). Furthermore, the Ease of Excitation and the Low Sensory Threshold were shown to be negatively correlated with the sense of coherence, comprehensibility, manageability, 
meaningfulness, self-efficacy; these positively correlated with alienation, work stress and displeasure (Evers, Rasche, \& Schabracq, 2008), anxiety, depression, poor social skills, poor attention to details, and difficulty describing and identifying feelings (Liss, Mailloux, \& Erchull, 2008). At the same time, the Aesthetic Sensitivity subscale was found to be related to greater attention to details, internally-oriented thinking, and better communication skills (Liss at al., 2008). These findings support the view that for aesthetically sensitive people, their sensitivity is not debilitating, but rather it further enhances their complex inner lives. In the current study, I relied on Smolewska's et al. (2006) three-factor structure of the Highly Sensitive Person Scale in attempting to replicate their patterns of correlations between the HSPS, its subscales, and measures of the behavioural inhibition system (BIS) and behavioural activation system (BAS), as well as the Big Five Inventory.

\section{Self-regulation and Ego-depletion}

Many actions are influenced by automatic and unconscious processes (Bargh, 1997), yet others are consequences of well-calculated, thoughtful moves. Whether conscious or unconscious, people's decisions and actions create their identities. Baumeister (1998) sees the human "self" as built out of three phenomena. The first one, the reflexive consciousness, through accumulation of knowledge, allows the human's self to form awareness of itself. It includes: self-awareness processes, self-knowledge, self-schemas, self-esteem, and processes of deception. The next building block of the self allows people to fulfil their fundamental motivation - it allows creating and maintaining relationships with others. This interpersonal aspect of self includes: self-presentation, adaptation to relationships, reciprocal interactions between interpersonal contexts, and various views of the self. The third phenomenon that constitutes the self, the executive function, allows the self to make choices, initiate actions, take 
responsibility, exert control, and, most crucial for individual and social well-being, it is able to regulate itself. The process of self-regulation makes one's behaviour more flexible. Being able to alter one's actions permits an urge to be controlled, prevents unwanted responses, and brings one's behaviour into line with moral or societal standards (Baumeister, 1998; Baumeister, Vohs, \& Tice, 2007; Fishbach \& Labroo, 2007; Logue, 1988). Self-regulation ability is central in reduction of susceptibility to alcohol and drug use, smoking, overeating, crime and violence, teen pregnancy, sexually transmitted diseases, mental and physical health problems, as well as school, work, and financial difficulties (Baumeister, Heatherton, \& Tice, 1994; Duckworth \& Seligman, 1994; Gailliot \& Baumeister, 2007; Levy, 2006; Mischel, Shoda, \& Peake, 1990; Muraven \& Baumeister, 2000; Tangney, Baumeister, \& Boone, 2004; Wills \& Stoolmiller, 2002).

The self-regulation changes are often explained through the reference to the strength or energy model. This model presupposes that since tempting impulses have certain strengths, the self-regulation also needs to possess at least the same amount of strength to resist them. Therefore, just like a muscle that is fatigued after a workout, an act of self-regulation (through expending a person's energy or strength resources) will impair the consequent self-regulations, creating a state of ego-depletion (Baumeister, Bratslavsky, Muraven, \& Tice, 1998; Muraven \& Baumeister, 2000; Vohs \& Heatherton, 2000). The muscle comparison goes even further, suggesting that just like a muscle is able to regain its strength through relaxation or chemical enhancements, so too can a person's ego-depletion be reversed through rest and relaxation (Tyler \& Burns, 2008), and/or by restoring blood glucose (Gailliot et al., 2007). Furthermore, just like the constant training of a muscle increases its strength, it is also possible to reduce the effects of ego-depletion by regularly performing tasks requiring self-regulation (Gailliot, Plant, Butz, \& Baumeister, 2007; Muraven, Baumeister, \& Tice, 1999; Oaten \& Cheng, 2006a, 2006b, 2007). 
The strength model of self-regulation, discussed above, has been supported by a series of studies, which used the same resource for suppressing thoughts, amplifying emotions, physical stamina, impulse control, and persistence in the face of failure, supporting the notion that the different acts of self-regulation seem to draw on a common, limited resource (Baumeister, 2000; Muraven, Tice, \& Baumeister, 1998). Furthermore, the majority of these studies evoke the state of ego-depletion by using an executive function of the self, which places demands on cognitive systems, for example by constantly maintaining and updating memory. The commonly used techniques require participants to override their habitual or dominant response, whether by suppressing emotions, resisting temptations, or by making an active choice, a technique which was applied in the current study (Muraven, Tice, \& Baumeister, 1998; Baumeister, Bratslavsky, Muraven, \& Tice, 1998; Tyler, 2008; Wright, Martin, \& Bland, 2003). Specifically, based on the notion that active responses engage the self, and therefore leave stronger psychological aftereffects than passive, i.e. less consciously made, choices (Allison \& Messick, 1988; Cioffi \& Garner, 1996; Fazio, Sherman, \& Herr, 1982), led Baumeister, Bratslavsky, Muraven, and Tice (1998). This is compared to the finding that participants, who had to cross all letters $e$ in a text and later were told to override this habitual response by crossing only letters $e$ based on specific rules, were more depleted than participants in a control group, who worked on arithmetic problems, not involving the use of the self.

\section{Alternative Explanations of Ego-depletion}

Not everybody is convinced that the ego-depletion is the cause of diminished cognitive performance on subsequent tasks. A variety of possible explanations have been proposed as alternative explanations for ego-depletion.

Some researches saw an increase in fatigue levels (Friese, Hofmann, \& Wanke, 2008; 
Stewart, Wright, Hui, \& Simmons, 2009, Segerstrom \& Nes, 2007), while others blamed the deflated motivation or a decrease in participants' self-efficiency after performing costly selfregulating tasks (Boksem, Meijman, \& Lorist, 2006; Folkman \& Moskowitz, 2000; Leith \& Baumeister, 1996; Lorist, Boksem, \& Ridderinkhof, 2005; Mayer \& Gaschke, 1988; Tice, Bratslavsky, \& Baumeister, 2001; Tops, Lorist, Wijers, \& Meijman, 2004), as sources of reduced performance on subsequent tasks. Yet others claimed that fulfilling initial task demands could be mistakenly seen as fulfilling implicit contract with the researcher, resulting in exertion of less effort on consecutive task (Hagger, Wood, \& Stiff, 2010).

However, most of alternative explanations mentioned above, have been rebuffed by subsequent research findings. For example, Van den Berg (1985) and Hancock and Desmond (2000) found that fatigue cannot explain reduced performance on the subsequent task because it effects people's performance only on unimportant, simple tasks and not on important or complex goals. Also, the notion that initial tasks reduce participants' self-efficiency was discredited; Wallace and Baumeister's (2002) study giving people positive or negative feedback about their performance did not result in differences among participants' scores on the second, unsolvable puzzle task. Finally, various studies also falsified the experimenter demand explanation. It has been shown that even when the two self-regulatory tasks have been presented as two different experiments (Baumeister, Bratslavsky, Muraven, \& Tice, 1998; Burkley, 2008; Fischer, Greitemeyer, \& Frey, 2008; Seeley \& Gardner, 2003; Vohs, Baumeister, \& Ciarocco, 2005; Vohs \& Faber, 2007) or when the demand for the first task comes from someone other than the experimenter (Richeson \& Shelton, 2003; Richeson, Trawalter, \& Shelton, 2005; Vohs et al., 2008), participants still performed worse on the second task as a result of previous selfregulation. Therefore, it is safe to consider ego-depletion as a consequence of the expenditure of 
the self-regulation resources and a source of diminished cognitive functioning.

\section{Self-regulation and Ego-depletion as Dispositional Constructs}

Various theorists see a capacity for self-regulation as a dispositional concept, which differs across individuals (Funder, Block, \& Block, 1983; Metcalfe \& Mischel, 1999; Muraven \& Baumeister, 2000; Schouwenburg, 2004; Wills \& Dishion, 2004). It is possible that some people possess more self-regulatory energy or are able to control this energy better, which insulates them from the effects of ego-depletion. However, only a few studies investigated this idea (Baumeister, Gailliot, DeWall, \& Oaten, 2006). Specifically, high levels of ego-depletion have been found to be positively associated with a high orientation to others and low self-monitoring. This association has been attributed to the need of such people to meet the expectation of others and their need to live according to societal standards, which often requires overriding one's own desires, and therefore, results in an extensive expenditure of self-regulatory energy (Seeley \& Gardner, 2003; Wen Wan \& Sternthal, 2008). Furthermore, ego-depletion has been found to be positively correlated with fluid intelligence and with higher levels of consideration of future consequences, which could be explained by the fact that those people are possibly more prone to the situational demands of the tasks, which lead them to consume more self-regulatory energy (Joireman, Balliet, Sprott, Spangenberg, \& Schultz, 2008). The notion that some people are more prone to ego-depletion in specific situations was assessed in the current study. Specifically, I tried to determine whether individuals with different levels of the sensory processing sensitivity are more prone to ego-depletion in highly extraverted conditions.

\section{Rationale of the Study}

The current study was based on the idea that since people who are more sensitive are said to be more vigilant to environmental stimuli (Aron \& Aron, 1997), they possibly engage in a 
constant self-regulation to prevent over-arousal. Although this possibility has not been tested yet, it is plausible that, similarly to introverted people, who compromise their well-being by exhausting resources while acting counterdispositionally (Little, 2008), HSPs constant selfregulation could be the reason for the diminished amount of the overall energy available to them (Baumeister \& Vohs, 2007). The current study did not test specific elements of the above idea; instead, it relied on the above rationale in assessing the plausibility that more sensitive people exhibit an accelerated state of ego-depletion, which in turn could explain their poor cognitive and social performance.

To test this hypothesis, first I assessed participants' sensitivity level and then I egodepleted their resources through engaging them in the task consisting of finding and highlighting the letter "e" in texts. Furthermore, I randomly assigned half of the participants to hearing a constant background noise while performing the task, which should have been extra bothersome and more depleting to more sensitive people. The varying effects of this depleting task were assessed by measuring participants' cognitive performance on the Stroop (1935) test.

The secondary purpose of the study is to take part in the discussion assessing the reasons for the high sensitivity in people, and to possibly replicate Aron and Aron (1997) findings, which stated that a highly sensitive people are related to, but distinct from, socially introverted or neurotic ones.

\section{Hypotheses}

Hypothesis 1. Based on Aron and Aron's (1997) findings that high sensitivity is not related to, but rather it is only one of the dimensions of, broader introversion and neuroticism traits, I predicted that the Highly Sensitive Person scale would be weakly or moderately ${ }^{1}$,

\footnotetext{
'Throughout the current study the strength of correlations was assessed according to Cohen's (1988) guidelines:
} 
negatively, and significantly correlated with measures of extraversion, as measured by the Big Five Inventory and the Eysenck Personality Questionnaire' extraversion subscales. On the other hand, the Highly Sensitive Person scale would be weakly or moderately, but positively, and significantly correlated with measures of neuroticism, as measured by the Big Five Inventory and the Eysenck Personality Questionnaire' neuroticism subscales.

Hypothesis 2. Based on Smolewska, McCabe, and Woody's (2006) findings, I predicted that the Ease of Excitation and the Low Sensory Threshold subscales would show weak or moderate positive correlations with the extraversion subscales, as well as weak or moderate but negative correlations with the neuroticism subscales.

Furthermore, based on the notion that highly sensitive people are characterized by a more active behavioural inhibition system (Aron \& Aron, 1997; Gray, 1991), findings by Smolewska, McCabe, and Woody (2006), found that the behavioural inhibition system is more strongly associated with the Ease of Excitation Subscale of the HSPS, but shows much weaker associations with the Aesthetic Sensitivity and the Low Sensory Threshold Subscales, I proposed that the Highly Sensitive People's Ease of Excitation subscale would be moderately, positively, and significantly correlated with introversion, neuroticism, and BIS subscales, while the Highly Sensitive People's Low Sensory Threshold and the Aesthetic Sensitivity subscales would exhibit positive and significant, but much weaker correlation with the introversion, neuroticism, and BIS measures.

Hypothesis 3. Sensitivity will moderate the effect of noise on cognitive performance.

Hypothesis 3a. I predicted that the main effect of noise and the main effects of sensitivity would be both significant, i.e., there would be a significant difference in cognitive performance,

$\mathrm{r}=-/+0.10$ to $-/+0.29$ small (weak correlation)

$r=-1+0.30$ to $-/+0.49$ medium (moderate correlation)

$\mathrm{r}=. /+0.50$ to $-1+1.0$ large (strong correlation) 
as indicated by the Stroop task, depending on the noise levels (presence or absence of noise) and on participants' sensitivity levels. Specifically, I predicted that all participants in the noise condition would perform worse (slower) on the Stroop task compared to participants in the nonoise condition. Furthermore, in both conditions, more sensitive participants would perform worse than less sensitive people, while more sensitive people in the noise condition would perform the worst among all other participants, achieving the slowest time on the Stroop task.

Hypothesis 3 b. I predicted that there would be a significant interaction effect between levels of sensitivity and levels of noise, i.e. the high sensitivity, as measured by the HSPS and also by its three subscales separately, would intensify the effects of the noise condition, which would result in diminished cognitive performance.

Hypothesis 4. Working on a depleting task is potentially more taxing for more sensitive people, especially in the noise condition (an exploratory analysis).

Hypothesis $4 a$. Since more sensitive people lose more energy due to depletion, higher levels of sensitivity would be positively and significantly correlated with slower performance on the habit breaking task (Text 2). I predicted that this correlation would be stronger for the Ease of Excitation subscale than for the Low Sensory Threshold and the Aesthetic Sensitivity subscales. Furthermore, since the noise condition was designed to make the habit breaking task more depleting, I suspected that more sensitive participants in the noise condition would have the slowest performance on the habit breaking task.

Hypothesis 4b. Also, since the depleting text task and the depleting noise condition were assumed to have a bigger negative impact on energy levels and performance of more sensitive people, I predicted that their performance would result in lower levels of subjective vitality, higher levels of exerted effort, and as a result, higher levels of negative affect especially among 
more sensitive individuals in the noise condition.

\section{Method}

\section{Participants}

The one hundred and eighteen Carleton University students were recruited through the online SONA system, which allows participants to choose and sign up for a variety of studies currently taking place in the university. The study was advertised as "Personality and Cognitive Functioning". The participants were young $(M$ age $=19.96$ years, $S D=2.36$, Range $=18-31$ years), predominantly Caucasian (50.8\%), female $(62.7 \%)$, undergraduate students $(M=1.71$ year of study, $S D=0.90$ ), who were registered in the first or the second year psychology classes, and whose primary language was predominantly English (72.9\%). All participants received a 1.0 class credit for their one hour participation. Detailed sample demographics are provided in Table 1 , in Appendix A.

\section{Measures}

Demographic data. Participants completed a short questionnaire, which assessed their age, gender, ethnicity, primary language, and their year of study (Appendix B).

Personality traits. To address findings of Aron and Aron (1997), the BIS/BAS scales were used (Appendix C; Carver \& White, 1994). The BIS/BAS questionnaire is a 24-item scale which uses a four-point Likert scale $(1=$ very true for me, $4=$ very false for $m e)$ to assess personal sensitivity to the two motivational systems as proposed by Gray (1991). The BIS scale is a 7-item measure of the degree to which participants expect to feel anxious when confronted with cues of punishment. The 13-item BAS scale is a measure, which assesses degree, to which receiving a reward leads to positive emotions (reward responsiveness subscale -5 items); tendency to actively pursue appetitive goals (drive subscale -4 items); and participants' 
tendency to seek out and engage in potentially rewarding activities (fun seeking subscale -4 items). Both scales had reportedly good reliabilities of 0.78 for the BIS and between $0.70-0.75$ for BAS subscales (Smolewska, McCabe, \& Woody, 2006). The alpha coefficients in the current investigation reached similarly good scores of: 0.81 , for the BAS scale; 0.78 , for the BIS scale; and between 0.68 and 0.77 , for the BAS subscales.

The Eysenck Personality Questionnaire originally consisted of 90 items measuring extraversion, neuroticism, and psychoticism (Eysenck, Eysenck, \& Barrett, 1985). In the current study, I used only 44 items, which required participants to give a simple yes or no answer, assessing their extraversion/introversion and neuroticism/emotional stability levels (Appendix D). In their 1985 study, Eysenck, Eysenck and Barrett reported acceptable reliability coefficients for neuroticism subscale, ranging from 0.80 to 0.84 , and extraversion subscale, ranging from 0.84 to 0.88 . In the current study, I obtained comparable alpha coefficients of 0.86 and 0.82 , for the neuroticism and the extraversion subscales, respectably.

The 44-item multidimensional personality questionnaire, Big Five Inventory (BFI; John \& Srivastava, 1999), was used to assess introversion/extraversion and neuroticism/stability traits. The measure uses five-point Likert scale with answers ranging from: strongly disagree to strongly agree (see Appendix E). In their 1999 study, John and Srivastava reported the alpha reliability coefficient of 0.88 for extraversion subscale and 0.84 for neuroticism subscale. In the current study, I obtained similarly good alpha coefficients of 0.83 and 0.82 for the extraversion and the neuroticism subscales, respectively.

Sensitivity. The sensory processing sensitivity was assessed by the 27 -item Highly Sensitive People Scale (HSPS; Aron \& Aron, 1997). This scale requires subjects to use a sevenpoint Likert scale $(1=$ not at all, $7=$ extremely $)$ to rate their sensitivity to internal and external 
factors. The alpha reliability coefficient reported by Aron and Aron (1997) was acceptable 0.87 (Appendix F), which is comparable to the Cronbach's alpha of the present study $(\alpha=0.84)$. In the current study, in accordance with Smolewska's three-factor structure of the HSPS, I analyzed the HSPS as a whole but I also used the three separate sensitivity subscales into which the HSPS was divided (Smolewska, McCabe, \& Woody, 2006): 12-item ease of excitation, seven-item aesthetic sensitivity, and six-item low sensory threshold subscales. In the original investigation, the three subscales showed good internal consistency coefficients ranging between 0.72 and 0.81 . In the current investigation the Cronbach's alphas of these subscales ranged between 0.55 (for the aesthetic sensitivity) and 0.80 .

Ego-depletion. In order to ego-deplete participants, and based on the notion that all active choices, which use the power of self, leave stronger psychological aftereffects than passive ones (Allison \& Messick, 1988; Cioffi \& Garner, 1996; Fazio, Sherman, \& Herr, 1982), all participants were asked to work on a clerical task. I used two excerpts from Albert Einstein's book "Relativity: The Special and General Theory" (1920). The text A, in which participants were instructed to highlight every letter "e", was an example of a passive choice and was used to instil in participants the habit to responding to every "e". Next, the text B required them to highlight all of letters " $\mathrm{e}$ ", unless the "e" was next to a vowel, or if there was a vowel two letters removed. This text involved more active choice, which engaged the self of the participants into breaking the habit of highlighting every " $\mathrm{e}$ ", and which should have left them ego-depleted, as achieved in other studies (Baumeister, Bratslavsky, Muraven, \& Tice, 1998; DeWall, Baumeister, Gailliot, \& Maner, 2008). Each passage was proximately 500 words in length (Appendix G). In order to further deplete participants, I used a sound file obtained from the freeSFX webpage (http://www.freesfx.co.uk/soundeffects/ambiences_backgrounds/), with recorded noises 
of a busy New York cafe. It has been shown that an exposure to unpredictable stress causes depletion of self-resources. Unpredictable noise, being such a stressful stimulus, caused participants, who were working on unsolvable problem, to become frustrated much sooner than participants who did not hear any sound (Glass, Singer, \& Friedman, 1969). Therefore, the noise made up of background music, clanking of dishes, various intertwined conversations, and laughter, all happening unpredictably, and often simultaneously, should have been especially bothersome and stressful for people with the high sensory processing sensitivity. Being already depleted, and being extra sensitive to their environment, they should have had more trouble concentrating on the "e" highlighting tasks in such a loud conditions. They possibly had to use even more self-control power, resulting in them being much more depleted than less sensitive people.

Cognitive functioning. The computerized Stroop (1935) task was administered in order to assess the level of participants' cognitive functioning, and as a result, assessed the effects of the ego-depletion task. The test was implemented on iMac G3 computers using the SuperLab 4 software package developed by Cedrus, Inc. During the Stroop task, participants were required to name the colour of ink in which the words are printed, ignoring the meaning of the words. The difficulty of the test lied in the fact, that the words themselves represented names of colours. Therefore, naming words congruent with the colour, in which they were printed (e.g., the word blue printed in blue ink), was expected to take shorter time than naming words incongruent with the colour, in which they were printed (e.g., the word green printed in red ink). The computer presented 300 trials of randomly mixed congruent and incongruent words, and participants responded by pressing the key which colour matched the colour of the word on the screen. The test took approximately 10 minutes to complete. Since previous research has found ego-depletion 
effects on incongruent Stroop trials, but not on the congruent ones (Inzlicht \& Gutsell, 2007), the final score of the test was based on response time and accuracy on incongruent trials.

Affect, vitality, and effort. Participants' affect was assessed by administrating the Positive Affect Negative Affect Schedule (PANAS; Watson, Clark, \& Tellegen, 1988). The PANAS is a 20 -item measure of positive and negative affect states. Participants were required to indicate the extent of their feelings by rating each presented item on a 5-point scale ranging from $1=$ very slightly or not at all to $5=$ extremely (see Appendix $\mathrm{H})$. Watson, Clark, and Tellegen (1988) reported good reliability of both subscales. The Cronbach's alpha coefficients ranged from 0.86 to 0.90 for the Positive Affect Scale and from 0.84 to 0.87 for the Negative Affect Scale. Furthermore, test-retest correlations for an 8-week period were reported between 0.47 and 0.68 for the Positive Affect and 0.39-0.71 for the Negative Affect. The PANAS has been shown to have a strong reported validity, since measures of general distress and dysfunction, depression, and state anxiety are more highly correlated with the Negative Affect Scale than with the Positive Affect Scale. In the current study, the PANAS Positive Affect scale reached alpha coefficient of 0.92, while the PANAS Negative Affect reached alpha coefficient of 0.80 , showing similarly strong validity of these scales.

Participants' vitality was assessed with the Subjective Vitality Scale (Bostic, Rubio, \& Hood, 2000; Ryan \& Frederick, 1997), which is a 6-item measure used here to assess the extent to which participants feel alive and are aware of having energy available to the self at that specific moment in time. Participants were required to indicate the degree to which the six statements (e.g. I feel alive and vital) are true for them on a 7-item scale ranging from $1=$ not at all true to 7 = very true (see Appendix I). The Subjective Vitality Scale was reported to have a good internal consistent reliability ranging from 0.80 to 0.89 , which was comparable to alpha 
coefficient obtained in the current study $(\alpha=0.84)$.

Finally, the effort expended by participants during the study was assessed by asking participants to use 5-point Likert scale $(1=$ very slightly or not at all to $7=$ extremely $)$ to provide answers to four questions obtained from Gallagher, William, and Fleeson's (2011) work (e.g. How effortful was it to act according to the instructions you were given?). The Effort Scale (see Appendix $\mathrm{J}$ ) was reported to have a good internal reliability of 0.85 , however in the current study, the alpha coefficient of this scale reached only 0.60 .

\section{Procedure}

Participants were able to find and sign in for the study through the SONA system. They were told the study was testing differences in mental functioning among people with different personality traits. This study required a single-time lab attendance and each session was run with a total of up to three independently working participants (i.e., in separate rooms, but run simultaneously).

After arriving at the lab, all subjects were required to sign an informed consent form, which stated the purpose of the study and confidentiality protecting procedures. It also assured them of an ability of withdrawing from the study without any penalty. At this time, each participant received their participation number, which enabled linking various parts of the experiment done by the same person. The participants' confidentiality was preserved, since their participation numbers were separated from their informed consent forms, and their names were only used for assessing participation credits to the subjects. Next, the participants were taken to separate, small rooms, containing a desk and a computer. They were all required to fill out questionnaires on demographics, measure of sensitivity, and measure of personality traits, after which they were instructed to put the headphones on. In order to deplete participants' self- 
control resources, all participants were asked to work on two different texts. The text A required them to highlight every letter " $\mathrm{e}$ " and after that, they were asked to highlight all of letters "e" in the text B, unless the "e" was next to a vowel or if there was a vowel two letters removed from it. Participants were given only 10 minutes to work on each text. To further deplete participants, all of them wore headphones and all of them were instructed that they may, or may not, hear something while working on both texts. Half of them, the control group, were not exposed to any sounds. They heard nothing in their headphones, which should have further buffered any outside sounds. On the other hand, the experimental group heard a constant noise, similar to the one experienced in a busy cafe or restaurant. Immediately after the texts A and B, participants were asked to take off their headphones, and they performed a computerized version of the Stroop task (Stroop, 1935), which allowed me to assess the levels of their mental depletion. Next, participants were asked to complete the measures of their positive and negative affects, as well as the measure of their vitality. The last step of the experiment consisted of debriefing participants, during which I further explained the nature of the study, answered any questions they had, provided contact information for help centres in Ottawa and within Carleton University in case participants found the study had aversive effects on their well-being, as well as resources allowing students to deepen their knowledge about highly sensitive people and the notion of egodepletion. Since this study did not use any extreme form of depletion, and since depletion occurs naturally in everyday life, the restoration of participants' self-control resources after the study was not needed.

\section{Data cleaning}

Three participants were excluded from analyses due to their performance on the Stroop task. Out of those three participants, two were outliers due to excessive number of committed 
mistakes (247 and 125 mistakes in 325 trials), indicating a problem with following the Stroop task's instructions. Yet another participant was excluded due to her significantly longer response times on all of the output variables of the Stroop task, as well as due to her being significantly different from other participants on demographic variables (age: 51, primary language: Farsi).

In the current analysis, the univariate outliers ( $Z$-scores exceeding the critical value of $+/-$ 3.29 SD) were assessed by examining scores of all participants in the entire sample simultaneously, as well as by examining scores of participants in both conditions (noise and no noise) separately. Both analyses yield similar outliers, which were changed to the second lowest/highest score not exceeding $+/-3.29 \mathrm{SD}$. Such extreme scores were found and adjusted among the BAS, the BAS Fun Seeking, and the BAS Reward Responsiveness subscales, as well as among the PANAS Negative Affect subscale. ${ }^{2}$ Subsequent analysis of new Z-scores of the scales did not indicate existence of any new univariete outliers.

During the regression analyses, I also analyzed the existence of multivariate outliers by calculating the critical values and examining graphs of the centered leverage values, the externally studentized residuals, and the difference in fit standardized. To examine the extent to which such outliers were influencing the analysis, I analyzed data with those outliers in it and again after excluding them from the data. Both analyses led to similar results, indicating the outliers had little impact on the analysis; therefore I decided to keep them within our data.

\section{Results}

\section{Descriptive statistics and correlations}

The first step of the analysis was to obtain the descriptive statistics of all the measures used

\footnotetext{
${ }^{2}$ For example, within the BAS subscale, the score of $23(z=-3.53)$ was changed to the second lowest score of $26-$ $1=25(z=-3.19)$; or within BAS Fun Seeking subscale, the score of $4(z=-3.77)$ was changed to second lowest score of $6-1=5(z=-3.39)$, which still exceeded the critical value, therefore the score was changed to $6(z=-2.98)$.
} 
in the current study (see Table 2 in Appendix A). Next, as seen in Table 3, my analysis indicated that there was a strong, positive, and significant relationship between BAS and its subscales, as well as between the extraversion - introversion subscales of the Big Five Inventory and the Eysenck's Personality Questionnaire. Furthermore, all of the above scales were strongly or moderately, positively, and significantly correlated with each other, indicating that they measured similar personality dimensions.

The next step of the analysis indicated that, as hypothesized, neuroticism - emotional stability subscales of the Big Five Inventory and the Eysenck's Personality Questionnaire's neuroticism subscales, as well as the BIS, all measure similar constructs since they were strongly, positively, and significantly intercorrelated. Ultimately, the above analyses supported the validity of the majority of the scales used to measure the personality traits of introversionextraversion and neuroticism-emotional stability. 
Table 3

Correlations between Sensitivity, Extraversion/Introversion, Emotional Stability/Neuroticism, and the BIS/BAS Measures

\begin{tabular}{|c|c|c|c|c|c|c|c|c|c|c|c|c|c|}
\hline Measure & HSP & $\begin{array}{l}\text { HSP } \\
\text { EoE }\end{array}$ & $\begin{array}{l}\text { HSP } \\
\text { LST }\end{array}$ & $\begin{array}{c}\text { HSP } \\
\text { AS }\end{array}$ & $\begin{array}{l}\text { BFl } \\
\text { Extra }\end{array}$ & $\begin{array}{l}\text { EPQ } \\
\text { Extra }\end{array}$ & $\begin{array}{c}\text { BFI } \\
\text { Neuro }\end{array}$ & $\begin{array}{c}\text { EPQ } \\
\text { Neuro }\end{array}$ & BIS & BAS & $\begin{array}{l}\text { BAS } \\
\text { Drive }\end{array}$ & $\begin{array}{l}\text { BAS } \\
\text { Fun }\end{array}$ & $\begin{array}{c}\text { BAS } \\
\text { Reward }\end{array}$ \\
\hline HSP & 1 & $0.89^{* *}$ & $0.72^{* *}$ & $0.47^{* *}$ & $-0.26^{* *}$ & $-0.30^{* *}$ & $0.44 * *$ & $0.47 * *$ & $0.48^{* *}$ & -0.15 & $-0.19^{*}$ & -0.15 & -0.02 \\
\hline HSP EOE & - & 1 & $0.56^{* *}$ & $0.19^{*}$ & $-0.37 * *$ & $-0.37 * *$ & $0.53^{* *}$ & $0.52^{* *}$ & $0.59^{* *}$ & -0.17 & $-0.26^{* *}$ & -0.17 & 0.07 \\
\hline HSP LST & - & - & 1 & $0.20^{*}$ & -0.11 & $-0.24 * *$ & $0.26^{* *}$ & $0.25 * *$ & $0.31^{* *}$ & -0.14 & -0.08 & $-0.18^{*}$ & -0.06 \\
\hline HSP AS & - & - & - & l & 0.14 & 0.11 & -0.06 & 0.06 & -0.06 & 0.11 & 0.05 & 0.12 & 0.08 \\
\hline BFI Extra & - & - & - & - & 1 & $0.66^{* *}$ & $-0.37 * *$ & $-0.41^{* *}$ & $-0.26 * *$ & $0.41^{* *}$ & $* 0.33 * *$ & $0.38^{* *}$ & ${ }^{*} 0.24^{* *}$ \\
\hline EPQ Extra & - & - & - & - & - & 1 & $-0.48^{* *}$ & $-0.45^{* *}$ & $-0.28^{* *}$ & $0.42 * *$ & $* 0.37^{* *}$ & $0.43^{* *}$ & 0.16 \\
\hline BFI Neuro & - & - & - & - & - & - & 1 & $0.79^{* *}$ & $0.63^{* *}$ & $-0.25^{* *}$ & $-0.30^{*}$ & $-0.28^{* *}$ & $* 0.03$ \\
\hline EPQ Neuro & - & - & - & - & - & - & - & 1 & $0.60^{* *}$ & -0.18 & $-0.22^{*}$ & -0.17 & -0.01 \\
\hline BIS & - & - & - & - & - & - & - & - & 1 & -0.15 & $-0.29 * *$ & -0.15 & 0.13 \\
\hline BAS & - & - & - & - & - & - & - & - & - & 1 & $0.82^{* *}$ & $0.81^{* *}$ & $0.69^{* *}$ \\
\hline BAS Drive & - & - & - & - & - & - & - & - & - & - & 1 & $0.52 * *$ & $0.32^{* *}$ \\
\hline BAS Fun & - & - & - & - & - & - & - & - & - & - & - & 1 & $0.37^{* *}$ \\
\hline BAS Reward & - & - & - & - & - & - & - & - & - & - & - & - & 1 \\
\hline
\end{tabular}

Note $1:{ }^{*} \mathrm{p}<0.05$ (two-tailed), ${ }^{* *} \mathrm{p}<0.01$ (two-tailed)

Note $2: \mathrm{HSP}=$ The Highly Sensitive Person scale; HSP EoE $=$ The Highly Sensitive Person scale

Ease of Excitation subscale; HSP LST = The Highly Sensitive Person scale Low Sensory

Threshold subscale; HSP AS = The Highly Sensitive Person scale Aesthetic Sensitivity; BFI

Extra/Neuro $=$ The Big Five Inventory's Extraversion/Neuroticism subscale; EPQ Extra/Neuro =

The Eysenck Personality Questionnaire's Extraversion/Neuroticism subscale; BIS = The

Behavioral Inhibition Subscale of the BIS/BAS scale; BAS = The Behavioral Activation

Subscale of the BIS/BAS scale; BAS Drive = The BAS' Drive subscale; BAS FunSeek $=$ The

BAS' Fun Seeking subscale; BAS Reward = The BAS' Reward Responsiveness subscale. 
It is also worth mentioning that the analyses indicated no significant differences between participants in both conditions (noise vs. no-noise) in terms of extraversion, neuroticism, BISBAS strength, and sensitivities; therefore, the random assignment to both conditions was accomplished successfully. Furthermore, to test whether the "e" searching task was more depleting in the noise condition compared to the no-noise condition; I assessed the number of mistakes made by participants in both texts separately. Contrary to expectations, there was no difference in the number of mistakes committed by the participants of both groups in Text B, which was designed to break the previously installed habit, therefore leading to ego-depletion. Yet, the number of mistakes committed by participants in Text A, a much easier task installing the habit of crossing every letter "e", was significantly higher in no-noise condition than the number of mistakes committed by participants in the same text in the noise condition $(t(116)=$ $2.04, p<0.05)$. This pattern of findings could indicate a possible rapid habituation to the noise used in the experiment (differences were gone by Task B). This interpretation was further supported by analyses which showed that the number of mistakes in Text A, but not in Text B, was significantly correlated with the outcome of the Stroop task, i.e. with the response time on incongruent, correct trials $(r(116)=0.22, p<0.05)$, the Highly Sensitive Person scale $(r(116)=$ $0.22, p<0.05)$, and with its Low Sensory Threshold subscale $(r(116)=0.23, p<0.05){ }^{3}$

\section{Hypotheses 1 and 2}

I predicted that the Highly Sensitive Person scale would be weakly or moderately, negatively correlated with measures of extraversion, and weakly or moderately, but positively correlated with measures of neuroticism. The analyses indicated that, as hypothesized, the

\footnotetext{
${ }^{3}$ Further analysis of the performance on the depleting tasks indicated that the participants who spent more time completing Text $A$, spent more time working on the Text $B(r(116)=0.32, p<0.001)$. Also, the participants, who completed more lines of the text $A$, completed more lines of the text $B$ as well $(r(116)=0.41, p<0.001)$, while the number of mistakes made in the text $A$ was positively and significantly correlated with the number of mistakes done in text $B(r(116)=0.32, p<0.001)$.
} 
Highly Sensitive Person scale was weakly, negatively, and significantly correlated with the extraversion subscale of the Big Five Inventory $(r=-0.26, p<0.05)$ and moderately and negatively correlated with the Eysenck Personality Questionnaire $(r=-0.30, p<0.001)$. Also, as predicted, the HSPS was moderately, positively, and significantly correlated with the neuroticism scales of the Big Five Inventory $(r=0.44, p<0.001)$ and the Eysenck Personality Questionnaire $(r=0.47, p<0.001)$.

Furthermore, I predicted that the correlations between the neuroticism and extraversion subscales and only the Ease of Excitation and the Low Sensory Threshold subscales would be weakly or moderately, and positively correlated with extraversion measures, while they would be weakly or moderately, but negatively correlated with measures of neuroticism. I also proposed that the Highly Sensitive People's Low Sensory Threshold and the Aesthetic Sensitivity subscales would exhibit positive and significant, but much weaker correlation with the introversion, neuroticism, and BIS measures, compared to the correlations of the Ease of Excitation subscale.

As indicated in Table 3, the results mostly supported my prediction. Specifically, the Ease of Excitation subscale showed moderate, negative, and significant correlations with extraversion subscales, as well as moderate, significant, but strong, positive correlations with the neuroticism subscales of the Big Five Inventory and the Eysenck Personality Questionnaire. On the other hand, the Low Sensory Threshold showed small, negative, and significant correlations with only the extraversion subscale of the Eysenck Personality Questionnaire. However, as expected, the Low Sensory Threshold subscale was weakly, positively, and significantly correlated with both of the neuroticism subscales of the above personality scales. Furthermore, as expected, the Aesthetic Sensitivity subscale's correlations had a dramatically different character, as all of them were found to be non-significant. Further analysis supported my 
hypothesis, showing that the Ease of Excitation's correlations with both neuroticism subscales were significantly stronger than those of Low Sensory Threshold (BFI: $z=-3.47, p<0.001$; EPQ: $z=-3.44, p<0.001$ ). Similarly, the correlation of the BIS subscale and the Ease of Excitation was significantly stronger than the correlation of the BIS and the Low Sensory Threshold $(z=-3.83, p<0.001)$. On the other hand, the correlation between the Ease of Excitation and the EPQ's introversion-extraversion subscale was only marginally stronger than the correlation of the Low Sensory Threshold $(z=1.54, p=0.06)$.

Overall, the above results indicate that the Highly Sensitive Person scale should not be considered as a single measure of sensory processing sensitivity, but rather as a measure of three different types of sensitivities, which supports the notion of Smolewska, McCabe, and Woody (2006). Furthermore, the weak to moderate correlations between sensitivity measures and the measures of neuroticism-emotional stability and introversion-extraversion indicate that, indeed, high sensitivity is distinct from those personality traits, yet it is related to them.

\section{Hypotheses 3, 3a, and 3b}

I predicted that the regression of cognitive performance on the noise vs. no noise condition would be moderated by the sensory processing sensitivity. Specifically, I hypothesised that there would be a significant difference in cognitive performance, as indicated by the Stroop task, depending on the noise levels (presence or absence of noise) and on the participants' sensitivity levels. ${ }^{4}$

First, I predicted that all participants in the noise condition would perform worse on the Stroop task compared to participants in the no-noise condition. The analysis, presented in Table 4, which involved four regression models in which the HSP scale and its three subscales were

\footnotetext{
${ }^{4}$ Due to a lack of consensus about which of the outcomes of the Stroop task constitutes the best measure of cognitive performance, I used two Stroop task variables as dependent variables, as well as four moderators (the HSP scale and the its three subscales) in my analyses, resulting in eight separate moderation models.
} 
used as moderators and where the mean response time of incongruent, correct trials on the Stroop task, was a dependent variable, all yield non-significant results. 
Table 4

Moderating effects of sensory processing sensitivity on regression of cognitive functioning (measured by the mean response time on correct, incongruent trials) with noise/no noise condition

\begin{tabular}{|c|c|c|c|c|c|}
\hline Predictor & $B$ & $t$ & sig. $(p)$ & $d f$ & Overall Statistics \\
\hline \multicolumn{6}{|l|}{ Model 1} \\
\hline Condition & 25.92 & 1.04 & 0.30 & 114 & $R^{2}=0.04$ \\
\hline HSP & 18.22 & 0.69 & 0.49 & 114 & $\Delta R^{2}=0.003$ \\
\hline Condition $\mathrm{x}$ HSP & 21.72 & 0.60 & 0.55 & 114 & $F=0.36, p=0.55$ \\
\hline $\mathrm{At}+1 \mathrm{SD}$ & 40.91 & 1.16 & 0.76 & 114 & Power of interaction $=$ \\
\hline At $-1 \mathrm{SD}$ & 10.93 & 0.31 & 0.25 & 114 & $=0.51$ \\
\hline \multicolumn{6}{|l|}{ Model 2} \\
\hline Condition & 25.57 & 1.03 & 0.30 & 114 & $R^{2}=0.04$ \\
\hline HSP EoE & 21.73 & 1.07 & 0.29 & 114 & $\Delta R^{2}=0.001$ \\
\hline Condition $x$ HSP EoE & 10.42 & 0.38 & 0.70 & 114 & $F=0.15, p=0.70$ \\
\hline $\mathrm{At}+1 \mathrm{SD}$ & 35.05 & 0.10 & 0.32 & 114 & Power of interaction $=$ \\
\hline $\mathrm{At}-1 \mathrm{SD}$ & 16.09 & 0.43 & 0.65 & 114 & $=0.64$ \\
\hline \multicolumn{6}{|l|}{ Model 3} \\
\hline Condition & 24.33 & 0.97 & 0.33 & 114 & $R^{2}=0.03$ \\
\hline HSP LST & 7.05 & 0.44 & 0.66 & 114 & $\Delta R^{2}=0.004$ \\
\hline Condition $x$ HSP LST & 15.65 & 0.68 & 0.50 & 114 & $F=0.46, p=0.50$ \\
\hline $\mathrm{At}+1 \mathrm{SD}$ & 41.39 & 1.17 & 0.24 & 114 & Power of interaction $=$ \\
\hline At $-1 \mathrm{SD}$ & 7.27 & 0.20 & 0.84 & 114 & $=0.37$ \\
\hline \multicolumn{6}{|l|}{ Model 4} \\
\hline Condition & 26.61 & 0.10 & 1.05 & 114 & $R^{2}=0.01$ \\
\hline HSP AS & -4.11 & -0.22 & -0.15 & 114 & $\Delta R^{2}=0.003$ \\
\hline Condition $\mathrm{x}$ HSP AS & 21.45 & 0.50 & 0.62 & 114 & $F=0.37, p=0.54$ \\
\hline$A t+1 S D$ & 42.48 & 1.18 & 0.24 & 114 & Power of interaction $=$ \\
\hline At $-1 \mathrm{SD}$ & 10.74 & 0.29 & 0.77 & 114 & $=0.20$ \\
\hline
\end{tabular}

Note 1: Model 1: Predictor $=$ Condition (noise vs. no noise), Moderator $=$ Highly Sensitive Person scale, Outcome $=$ Mean response time on incongruent, correctly done trials in the Stroop task; Model 2: Predictor $=$ Condition $($ noise vs. no noise), Moderator $=$ Highly Sensitive Person scale`s Ease of Excitation subscale, Outcome = Mean response time on incongruent, correctly done trials in the Stroop task; Model 3: Predictor $=$ Condition (noise vs. no noise), Moderator = Highly Sensitive Person scale's Low Sensory Threshold subscale, Outcome $=$ Mean response time on incongruent, correctly done trials in the Stroop task; Model 4: Predictor $=$ Condition (noise vs. no noise), Moderator = Highly Sensitive Person scale's Aesthetic Sensitivity, Outcome $=$ Mean response time on incongruent, correctly done trials in the Stroop task. 
Regardless of the null results, further analyses showed that all of these measures had patterns similar to predictions. Specifically, across analyses, participants tended to perform better on the Stroop task in the no noise condition than they did in the noise condition.

Secondly, I predicted that in both conditions more sensitive participants would perform worse than less sensitive people. Indeed, as shown in Table 4 and Figure 1, in all cases but one sensitivity scale, more sensitive people performed worse in both conditions than less sensitive people, however that difference in performance was non-significant.

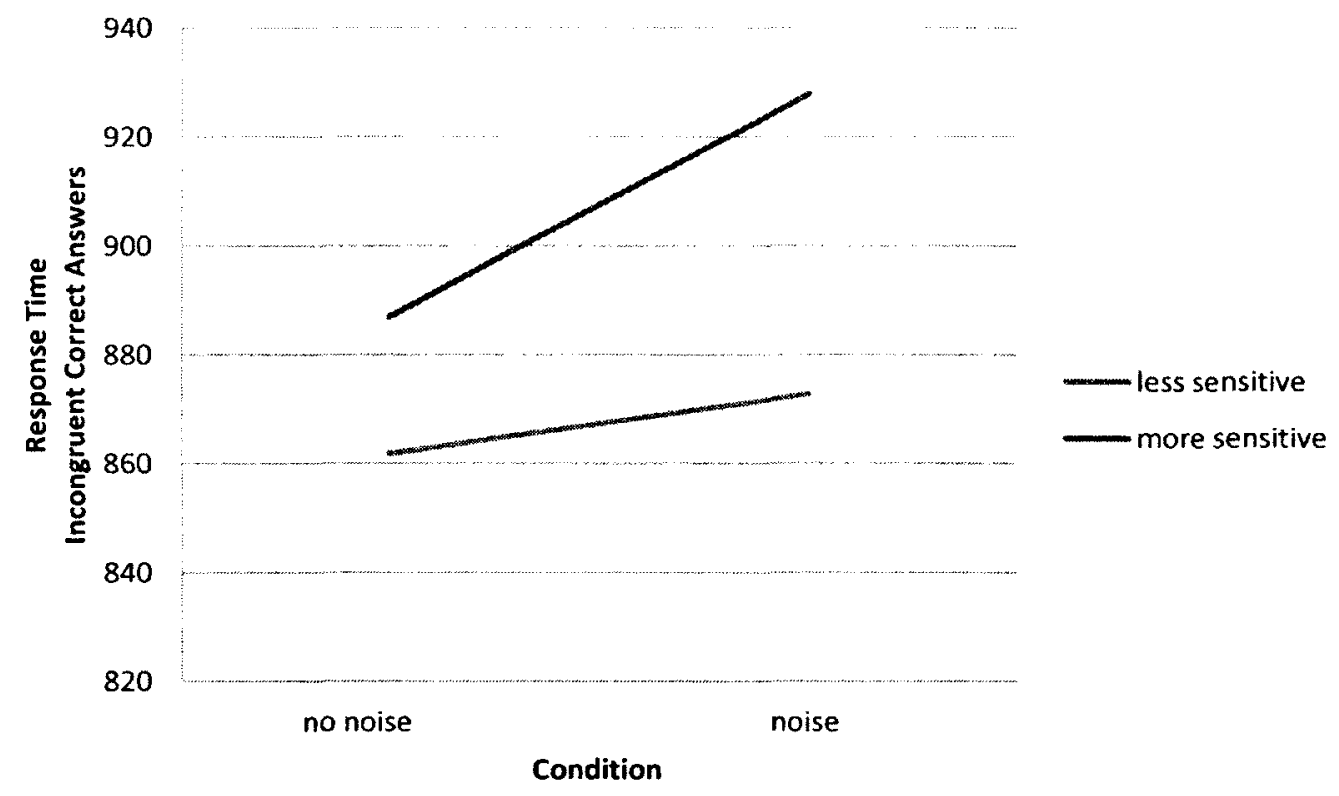

Figure 1. The moderating effect of sensitivity (measured by the Highly Sensitive Person scale) on the regression of cognitive functioning (measured as response time of the incongruent correct answers in the Stroop task) on two experimental conditions (noise vs. no noise) ${ }^{5}$.

\footnotetext{
${ }^{5}$ The effect presented in the Figure 1 was found to be not statistically significant.
} 
Furthermore, my hypothesis that more sensitive people in the noise condition would

achieve the slowest response time on the Stroop task was not supported. Although there was no

significant difference in response time of more and less sensitive people in the two conditions,

more sensitive people seemed to be more affected by the noise. More sensitive participants had a

more noticeable, yet non-significant, increase in their mean response time, showing that they

were them slower in their responses than less sensitive people. Overall, although the analyses

yielded null results, they also indicated a trend where, regardless of the experimental condition,

the cognitive performance of more sensitive people was slightly inferior to that of the less

sensitive participants. ${ }^{6}$

Hypotheses 4, 4a, and $4 \mathrm{~b}$

At the end of the study, participants were given three questionnaires: the Subjective

Vitality scale, PANAS' Negative Affect subscale, and the Effort scale, and they were asked to

\footnotetext{
${ }^{6}$ Subsequent analyses, in which the Stroop task's performance was assessed through the number of incongruent, correctly conducted trials, also resulted in non-significant findings. However, the pattern presented by the findings represented the predicted pattern: all participants performed more correct incongruent trials in the no noise condition than in the noise condition. Furthermore, more sensitive people (as measured by the HSPS, the Ease of Excitation and Low Sensory Threshold subscales) in the no noise condition performed more correct trails than less sensitive people. On the other hand, more sensitive people in the noise condition performed worse than less sensitive people. This pattern was not could not be extended to the more aesthetically sensitive people, who performed worse than less aesthetically sensitive people in the no noise condition, yet better than less sensitive people in the noise condition.

Further analyses, in which the personality traits of extraversion-introversion, neuroticism-emotional stability, and BIS-BAS were used as moderators of the effect of noise on cognitive performance (measured as a mean response time of correct incongruent trials, as well as a number of correctly completed, incongruent trials) also yield statistically non-significant results. Furthermore, I found that both more and less extraverted participants performed better in the no-noise condition than in the noise condition, with less extraverted participants being the most affected by the noise condition. These patterns were similar to the ones found during the BAS analysis, where people with less active BAS performed much better than participants with more active BAS in the no-noise condition, but their performance suffered in the noise condition and they performed worse in this condition than people with more active BAS. The results also pointed to the fact that more neurotic participants performed much better in the no-noise condition than in the noise condition - a pattern similar to the one found among participants with more active BIS. Furthermore, I found that the performance of more neurotic people in the no-noise condition was better, while in the noise condition was worse than that of less neurotic participants.
} 
answer those questionnaires in terms of how they felt in that particular moment in time. Since their mental energy was depleted, and later they had to engage in an effortful task, it was reasonable to assume that as vitally would be lower, their effort would be higher, and it would result in higher negative affect reports. As shown in Table 5, participants' effort was not correlated with their vitality levels $(r=0.11, \mathrm{~ns})$. However, high scores on the Effort scale and low scores on the Subjective Vitality Scale were both related to higher scores on the Negative Affect, with lower scores on the Positive Affect subscales of the PANAS.

Table 5

Correlations between Sensitivities, Subjective Vitality, Effort, and Affect Measures

\begin{tabular}{lcccccccc}
\hline Measure & HSP & $\begin{array}{l}\text { HSP } \\
\text { EoE }\end{array}$ & $\begin{array}{l}\text { HSP } \\
\text { LST }\end{array}$ & $\begin{array}{l}\text { HSP } \\
\text { AS }\end{array}$ & SVS & Effort & PANAS & \multicolumn{2}{c}{ PANAS } \\
\hline HSP & 1 & $0.89^{* *}$ & $0.72^{* *}$ & $0.47^{* *}$ & -0.07 & $0.23^{*}$ & -0.14 & $0.25^{* *}$ \\
HSP EoE & - & 1 & $0.56^{* *}$ & $0.19^{*}$ & -0.11 & 0.14 & $-0.21^{*}$ & $0.18^{*}$ \\
HSP LST & - & - & 1 & $0.20^{*}$ & -0.02 & $0.24^{* *}$ & -0.05 & $0.26^{* *}$ \\
HSP AS & - & - & - & 1 & 0.06 & 0.12 & 0.08 & 0.01 \\
SVS & - & - & - & - & 1 & 0.11 & $0.71^{* *}$ & $-0.22^{*}$ \\
Effort & - & - & - & - & - & 1 & $-0.20^{*}$ & $0.23^{*}$ \\
PANAS PA & - & - & - & - & - & - & 1 & -0.06 \\
PANAS NA & - & - & - & - & - & - & - & 1 \\
\hline
\end{tabular}

Note 1: ${ }^{*} \mathrm{p}<0.05$ (two-tailed); ${ }^{* *} \mathrm{p}<0.01$ (two-tailed)

Note 2: HSP $=$ The Highly Sensitive Person scale; HSP EoE $=$ The Highly Sensitive Person scale Ease of Excitation subscale; HSP LST = The Highly Sensitive Person scale Low Sensory Threshold subscale; HSP AS = The Highly Sensitive Person scale Aesthetic Sensitivity; Effort = The Effort scale; SVS = The Subjective Vitality scale; PANAS PA and NA = The Positive Affect Negative Affect Schedule 
Further analyses, as shown in Table 5, indicated that there was no significant correlation between subjective vitality and sensory sensitivity. However, people who scored higher on the HSP scale and its Low Sensory Threshold subscale reported exerting significantly more effort during the study. Correspondingly, those who scored higher on all of the sensitivity measures, except for the Aesthetic Sensitivity scale, reported significantly higher levels of negative affect right after completion of the habit breaking task and the Stroop task. ${ }^{7}$

\section{Discussion}

The main purpose of the present study was to assess whether people with more sensory sensitivity exhibit an accelerated state of ego-depletion, which in turn could potentially explain their poorer cognitive performance. This hypothesis was based on the notion that more sensory sensitive people are easily overwhelmed by a variety of sensory inputs, e.g. loud noises (Aron and Aron, 1997). Being so easily overstimulated could mean that those people try to control their responses (Baumeister, 1998; Baumeister, Vohs, \& Tice, 2007; Fishbach \& Labroo, 2007; Logue, 1988), and by doing so, they may expend the energy or strength resources available to them (Baumeister, Bratslavsky, Muraven, \& Tice, 1998; Muraven \& Baumeister, 2000; Vohs \& Heatherton, 2000). Therefore, I based my study on the idea that such a loss of self-regulating powers could result in a greater level of ego-depletion among more sensitive people.

Specifically, I tested whether more sensitive people exhibit an accelerated state of ego-depletion - a construct that I assessed through an analysis of participants' cognitive performances.

The analyses in the present study showed that there was no significant difference in cognitive performance of participants in the noise condition compared to those in the control

\footnotetext{
7 The subsequent analyses, in which the HSP scale and its subscales were each tested as moderators of effect of noise on effort (the Effort scale), subjective vitality (the SVS), and the negative affect (measured by PANAS) all showed null interactions. Further analyses of the simple slopes indicated that patterns did not support my predictions.
} 
condition, which indicated that the impact of the environmental stimulus of random chatter noise was not affected by the sensory processing sensitivity. However, regardless of the null results, the pattern of the results was similar to the pattern predicted in the hypothesis. Specifically, as predicted, all participants in the noise condition seemed to perform a bit worse on the Stroop task compared to participants in the no-noise condition, and more sensitive people in the noise condition achieved the slowest response time on the Stroop task. Furthermore, similarly to my prediction, in both conditions, more sensitive participants performed slightly worse than less sensitive people. These results could indicate that, indeed, as small as the effect was, the noise condition could possibly have had a negative, depleting effect on participants' cognitive performance, and that the more sensitive people differed slightly in their cognitive performance from less sensitive ones, since more sensitive people were potentially more depleted and performed the worst, regardless of the condition. It is important to restate, however, that all of these results were non-significant, therefore all of the above interpretations of the patterns cannot be considered definitive.

It is possible that the main idea on which the present study was based and which contains plausible, yet untested elements, does not represent the correct mechanisms explaining highly sensitive people's functioning. It is possible that more sensitive people do not engage in a constant self-regulation to prevent over-arousal, which, in turn, would diminish their energy levels. Instead, it is plausible that impaired cognitive and social performance of more sensitive people is a result of their past experiences. Inabilities to concentrate in a loud classroom or being uncomfortable in large crowds prevent such people from reaching their potential. In the long run, these poor social and professional performances of more sensitive people could lead to development of a state of learned helplessness, which would further prevent them from 
responding to potentially rewarding opportunities and challenges (Seligman, 1975).

Furthermore, it has been shown that highly sensitive people become overaroused when exposed to levels of stimulation considered normal for less sensitive people (Aron \& Aron, 1997). Studies have shown that being under influence of non-normative stimulation during periods of brain development leads to diminished cognitive performance. Specifically, excessive viewing of stimulating television programs by infants was shown to result in children's subsequent attention problems (Christakis, Zimmerman, DiGiuseppe, \& McCarty, 2004). Also, a study on mice indicated that newborn mice that were subjected to an auditory $(70 \mathrm{db})$ and visual stimulation (flashing lights) for six hours per day for a total of 42 days performed significantly worse cognitively compared to controls (Christakis, Ramirez, \& Ramirez, 2012). Therefore, it is possible that when young highly sensitive people were exposed to, what are considered normal levels of stimulation, for them those levels where high enough to interfere their brain development, leading to their problems with cognitive performance later in life. Of course this explanation also requires further research, and does not exhaust the possible mechanisms that might explain HSPs' difficulties.

Returning to the idea that self-regulation might still explain differences, it is possible that the small, statistically non-significant differences found between more and less sensitive people were due to the fact that more sensitive people have to create survival mechanisms in order to function in a world full of highly stimulating impulses. It is possible, therefore, that the longer they live around those stimuli, the better they become in desensitising or ignoring them, hence becoming more similar to their less sensitive colleagues. This is not to say that such people become less sensitive, but rather that they may adjust; they learn to dull their sensitivity in specific situations. This could perhaps also explain the different patterns found among the aesthetically sensitive 
people's results, which showed that the Aesthetic Sensitivity was not correlated with any of the personality traits: the BIS, neuroticism, nor introversion. It is possible that not all types of sensitivities lead to an increased usage of the self-regulation resources. Being more aesthetically sensitive means being more appreciative of a variety of arts, as well as being more creatively inclined (Aron and Aron, 1997). Therefore, aesthetic sensitivity is possibly the least handicapping type of sensitivity, since aesthetically sensitive people tend to be more likely to embrace their uniqueness and cultivate their sensitivity.

Furthermore, the unique character of Aesthetic Sensitivity subscale seems to support the notion of Smolewska, McCabe, and Woody (2006) that the Highly Sensitive People scale has a three-factor structure, measuring three distinctively different sensitivity types, from which aesthetic sensitivity is the most dissimilar. Specifically, although, the moderation analyses of the Aesthetic Sensitivity subscale also yield null results, the pattern among its simple slopes showed different patterns than those of other subscales. Furthermore, the strength of its correlations with other personality traits, as well as vitality, effort, and negative affect measures was also distinctively different.

It would seem that the unique character of the Aesthetic Sensitive (AS) subscale's analyses in the current study could lie in the low reliability of this Highly Sensitive Person's subscale. This low reliability could be the reason for obtaining small correlations, which could represent false null results. In fact, the reliability of the AS scale found in the current study $(\alpha=0.55)$ is the lowest as compared with reliabilities of the AS subscale found in previous studies. Liss, Mailloux, and Erchull (2008) reported Aesthetic Sensitivity subscale's alpha of 0.60; Evers, Rasche, and Schabracq (2008) reported alpha of 0.66, while Smolewska, McCabe, and Woody reported much higher reliability of the AS subscale $(\alpha=0.72)$. It is possible, therefore, that if the 
reliability of the Aesthetic Sensitivity subscale in the present study was better, its correlational analyses would resemble those of other two HSP Scale's subscales.

The secondary aim of the present study was to replicate Aron and Aron's (1997) findings and take part in the discussion about the relation of sensory sensitivity to introversion. The analyses supported my initial hypotheses, as well as replicated Aron and Aron's (1997) findings, since they indicated that the Highly Sensitive Person scale was weakly, negatively, and significantly correlated with measures of extraversion, and it was strongly, positively, and significantly correlated with measures of neuroticism.

Thus, the above findings seem to support the notion that high sensitivity is not exactly equivalent with introversion and neuroticism, yet, in accordance with Eysenck's model, it could be seen as one of the lower-order factors contained within above superfactors. Furthermore, the obtained moderate correlations between sensory processing sensitivity and the BIS fit into Gray's rotation of Eysenck's model. People with stronger BIS, i.e. more sensitive people, are said to be more anxious and as such are seen as more neurotic and a bit introverted (Gray, 1991). This notion was further supported by the results of the current study, which indicated that although high sensitivity is not equivalent with the above superfactors, it is closer to neuroticism than it is to introversion.

\section{Strengths and Limitations}

The measures used in the current study have been used in multiple previous investigations, and the fact that I was able to replicate previously reported correlational results corroborates their reliability and validity. Also, the ego-depleting, "e" crossing manipulation used in the current research has been shown to work successfully in previous studies (Baumeister, Bratslavsky, Muraven, \& Tice, 1998; DeWall, Baumeister, Gailliot, \& Maner, 2008). 
However, the present study had also few limitations. First, the interaction terms of the regression analyses had low power (shown in Table 4). Second, the study took place in an artificial lab environment, and although this resulted in good controllability, this setting was similar to the classroom environment and it could potentially evoke a well-learned school behaviour of externally elicited concentration. Third, I based the main manipulation of this study on the findings by Glass, Singer, and Friedman (1969), which showed that unpredictable noise can be a stressful stimulus, exposure to which causes premature depletion of self-resources. Trying to increase the generalizability of the study, I used real-life café chatter as my experimental manipulation instead of artificially generated noises; the results showed that this manipulation was not a perfect one, as it did not produce desired effects. The results indicated differences between no-noise and noise groups in the number of mistakes participants committed in the first (easier) text only. It is possible, therefore, that the noise participants heard during both tasks was bothersome enough only at the beginning. It is possible that listening to the same noises for ten minutes during two consecutive tasks resulted in the participants getting used to it and learning to ignore it. This interpretation was further enhanced by the fact that higher sensitivity was positively correlated with the number of mistakes, but again, only during completion of the first text. It is plausible that the noise was really bothersome for more sensitive people, depleting their resources and resulting in poorer performance, yet after a while, even more sensitive people were able to adjust to the new, noisy environment, especially that the noise was identical and predictable during both tasks.

All these limitations could be reasons for obtaining null results in the current study, yet it is possible that these limitations created only a poor experiment and that the null results would be obtained regardless of addressing these limitations. 


\section{Conclusion}

The present study brought support for Aron and Aron's (1997) notion that sensory processing sensitivity is a part of the broader traits of neuroticism and introversion. I was also able to support findings by Smolewska, McCabe, and Woody (2006) that highly sensitive people do not constitute a homogenous group and assessing it only as such could obscure some information about different types of sensitivities.

Since Western societies still encourage extraverted behaviours, making lives of introverts and more sensitive people challenging, I believe it is important and economically viable to learn more about the ways in which we could help introverted, neurotic, or sensitive people thrive. In the current study, I attempted to find out whether noisy environments especially impact more sensitive people. However, I was not able to prove that people with higher levels of sensory processing sensitivity exhibited an accelerated state of ego-depletion due to random noise, which in turn could explain their poorer cognitive performance. Nonetheless, the pattern which emerged during the study, and which was similar to the predicted one, could possibly indicate that more sensitive people differ from less sensitive people in their responses to the surrounding environment. Hopefully, future research will be successful in establishing that trend more firmly, which in turn may result in finding more helpful ways to conquer, or at least dull, the detrimental effects of high sensitivity. 


\section{References}

Allison, S. T., \& Messick, D. M. (1988). The feature positive effect, attitude strength, and degree of perceived consensus. Personality and Social Psychology Bulletin, 14, 231-241. doi: $10.1177 / 0146167288142002$

Anderson, J. R. (1982). Acquisition of cognitive skill. Psychological Review, 89, 369-406. doi:10.1037/0033-295X.89.4.369

Aron, E.N. (1996). The highly sensitive person: How to thrive when the world overwhelms you. New York: Broadway Books.

Aron, E.N. (2004). Revisiting Jung's concept of innate sensitiveness. Journal of Analytical Psychology, 49, 337-367. doi:10.1111/j.1465-5922.2004.00465.x

Aron, E. N., \& Aron A. (1997). Sensory-processing sensitivity and its relation to introversion and emotionality. Journal of Personality and Social Psychology, 73, 345-368. doi: $10.1037 / 0022-3514.73 .2 .345$

Bargh, J. A. (1997). The automaticity of everyday life. In R. S. Wyer, Jr. (Ed.), The automaticity of everyday life: Advances in social cognition (pp. 1-61). Mahwah, NJ: Erlbaum.

Barnes, G. (1975). Extraversion and pain. British Journal of Social and Clinical Psychology, 14, 303-308. doi:10.1111/j.2044-8260.1975.tb00182.x

Baumeister, R. F. (1998). The self. In D. T. Gilbert, S. T. Fiske, \& G. Lindzey (Eds.), Handbook of social psychology (4 ${ }^{\text {th }}$ ed., pp. 680-740). New York: McGraw-Hill.

Baumeister, R. F. (2000). Ego-depletion and the self's executive function. In A. Tesser, R. B. Felson, \& J. M. Suls (Eds.), Psychological perspectives on self and identity (pp. 9-33). Washington, DC: American Psychological Association. 
Baumeister, R. F., Bratslavsky, E., Muraven, M., \& Tice, D. M. (1998). Ego-depletion: Is the active self a limited resource? Journal of Personality and Social Psychology, 74, 12521265. doi:10.1037/0022-3514.74.5.1252

Baumeister, R. F., Heatherton, T. F., \& Tice, D. M. (1994). Losing control: How and why people fail at self-regulation. San Diego, CA: Academic.

Baumeister, R. F., \& Vohs, K. D. (2007). Self-regulation, ego depletion, and motivation. Social and Personality Psychology Compass, 11, 115-128. doi:10.1111/j.17519004.2007.00001.x

Baumeister, R. F., Vohs, K. D., \& Tice, D. M. (2007). The Strength Model of SelfControl. Current Directions in Psychological Science, 16, 351-355. doi:10.1111/j.14678721.2007.00534.x

Boksem, M. A. S., Meijman, T. F., \& Lorist, M. M. (2006). Mental fatigue, motivation and action monitoring. Biological Psychology, 72, 123-132. doi:10.1016/j.biopsycho.2005.08.007

Bostic T. J., Rubio D. M., \& Hood M. (2000). A validation of the subjective vitality scale using structural equation modelling. Social Indicators Research, 52, 313-324. doi:10.1023/A:1007136110218

Broadbent, D.E. (1979). Human performance and noise. In C.M. Harris (Ed.), Handbook of noise control (2nd ed.). New York: McGraw-Hill Book Company.

Burkley, E. (2008). The role of self-control in resistance to persuasion. Personality and Social Psychology Bulletin, 34, 419-431. doi:10.1177/0146167207310458

Buss, A. H., \& Plomin, R. (1984). Temperament: Early developing personality traits. Hillsdale, NJ: Erlbaum. 
Cain, S. (2012). Quiet: The power of introverts in a world that can't stop talking. New York, NY: Crown Publishers.

Carver, C. S.; White, T. L (1994). Behavioral inhibition, behavioral activation, and affective responses to impending reward and punishment: The BIS/BAS Scales. Journal of Personality and Social Psychology, 67, 319-333. doi:10.1037/0022-3514.67.2.319

Christakis, D. A., Ramirez, J. S. B., \& Ramirez, J. M. (2012). Overstimulation of newborn mice leads to behavioral differences and deficits in cognitive performance. Scientific Report, 2, 546. doi:10.1038/srep00546

Christakis, D. A., Zimmerman, F. J., DiGiuseppe, D. L., \& McCarty, C. A. (2004). Early television exposure and subsequent attentional problems in children. Pediatrics, 113 , $708-713$.

Cioffi, T. \& Garner, R. (1996). The Effect of Response Options on Decisions and Subsequent Behavior: Sometimes Inaction is Better. Personality and Social Psychology Bulletin, 24, 463-472. doi:10.1177/0146167298245002

Cohen, J. (1988). Statistical power analysis for the behavioural sciences (2nd Ed.).

Hillsdale, NJ: Lawrence Erlbaum Associates.

Corr, P. J. (2002). J.A. Gray's reinforcement sensitivity theory: Tests of the joint subsystems hypothesis of anxiety and impulsivity. Personality and Individual Differences, 33, 511 532. doi:10.1016/S0191-8869(01)00170-2

De Pascalis, V., Fiore, A., Sparita, A. (1996). Personality, event-related potential (ERP) and heart rate (HR): An investigation of Gray's theory. Personality and Individual Differences, 20, 733-746. doi:10.1016/0191-8869(96)00016-5

DeWall, C. N., Baumeister, R. F., Stillman, T. F., \& Gailliot, M. T. (2007). Violence restrained: 
Effects of self-regulation and its depletion on aggression. Journal of Experimental Social Psychology, 43, 62-76. doi:10.1016/j.jesp.2005.12.005

Duckworth, A.L., \& Seligman, M.E.P. (2005). Self-discipline outdoes IQ in predicting academic performance of adolescents. Psychological Science, 16, 939-944.

doi:10.1111/j.1467-9280.2005.01641.x

Edman, G., Schalling, D., \& Rissler, A. (1979). Interaction effects of extraversion and neuroticism on detection thresholds. Biological Psychology, 9, 41-47. doi:10.1016/0301$0511(79) 90021-8$

Einstein, A. (1920). Relativity: The special and general theory [Electronic version]. New York: Bartleby.com. Retrieved from Bartleby database.

Enns M. W., \& Cox B. J. (1997). Personality dimensions and depression: Review and commentary. Canadian Journal of Psychiatry, 42, 274-284.

Evers, A., Rasche, J., \& Schabracq, M. J. (2008). High sensory-processing sensitivity at work. International Journal of Stress Management, 15, 189-198. doi:10.1037/10725245.15 .2 .189

Eysenck, H. J. (1957). The dynamics of anxiety and hysteria. New York: Praeger.

Eysenck, H. J. (1967). The biological basis of personality. Springfield, IL: Charles C Thomas.

Eysenck, H. J. (1981). A model for personality. New York: Springer-Verlag.

Eysenck, H. J. (1991). Biological dimensions of personality. In L. A. Pervin (Ed.). Handbook of personality (pp. 244-276). New York: Guilford Press.

Eysenck, H. J. (1994). Personality: Biological foundations. In P. A. Vernon (Ed.). The neuropsychology of individual differences. London: Academic Press.

Eysenck, H. J., \& Eysenck, S. B. G. (1968). Manual for the Eysenck Personality Inventory. San 


\section{Diego, CA: EDITS.}

Eysenck, H. J., \& Eysenck, M. W. (1985). Personality and individual differences. New York: Plenum.

Eysenck, S. B., Eysenck, H. J., Barrett, P. (1985). A revised version of the Psychoticism scale, Personality \& Individual Differences, 6, 21-29. Retrieved Jan

Fazio, R. H., Sherman, S. J., \& Herr, P. M. (1982). The feature-positive effect in the selfperception process: Does not doing matter as much as doing? Journal of Personality and Social Psychology, 42, 404-411. doi:10.1037/0022-3514.42.3.404

Fischer, P., Greitemeyer, T., \& Frey, D. (2008). Self-regulation and selective exposure: The impact of depleted self-regulation resources on confirmatory information processing. Journal of Personality and Social Psychology, 94, 382-395. doi:10.1037/00223514.94.3.382

Fishbach, A., \& Labroo, A. (2007). Be Better or Be Merry: How Mood Affects Self-Control. Journal of Personality and Social Psychology, 93, 158-173. doi:10.1037/00223514.93.2.158

Folkman, S., \& Moskowitz, J. T. (2000). Positive affect and the other side of coping. American Psychologist, 55, 647-654. doi:10.1037/0003-066X.55.6.647

Fowles, D. C. (2006). Jeffrey Gray's contributions to theories of anxiety, personality, and psychopathology. In T. Canli (Ed.), Biology of personality and individual differences (pp. 7-34). New York: Guilford Press.

Freud, Sigmund (1923), Das Ich und das Es, Internationaler Psycho-analytischer Verlag, Leipzig, Vienna, and Zurich. In J. Riviere (Ed. and Trans.), The Ego and the Id. London: Hogarth Press and Institute of Psycho-analysis. 
Freud, S. (1961). The ego and the id. In J. Strachey (Ed. and Trans.) The standard edition of the complete psychological works of Sigmund Freud (pp. 3-66). London: Hogarth Press.

Friese, M., Hofmann, W., \& Wanke, M. (2008). When impulses take over: Moderated predictive validity of explicit and implicit attitude measures in predicting food choice and consumption behaviour. British Journal of Social Psychology, 47, 397-419. doi: $10.1348 / 014466607 \times 241540$

Funder, D. C., Block, J. H., \& Block, J. (1983). Delay of gratification: Some longitudinal personality correlates. Journal of Personality and Social Psychology, 44, 1198-1213. doi:10.1037/0022-3514.44.6.1198

Furnham, A., Chamorro-Premuzic, T., \& McDougall, F. (2002). Personality, cognitive ability, and beliefs about intelligence as predictors of academic performance. Learning and Individual Differences, 14, 47-64.

Gailliot, M. T., \& Baumeister, R. F. (2007). The physiology of willpower: Linking blood glucose to self-control. Personality and Social Psychology Review, 11, 303-327.

Gailliot, M. T., Baumeister, R. F., DeWall, C. N., Maner, J. K., Plant, E. A., Tice, D. M., Brewer, L. E., \& Schmeichel, B. J. (2007). Self-control relies on glucose as a limited energy source: Willpower is more than a metaphor. Journal of Personality and Social Psychology, 92, 325-336. doi:10.1037/0022-3514.92.2.325

Gailliot, M. T., Plant, E. A., Butz, D. A., \& Baumeister, R. F. (2007). Increasing self-regulatory strength can reduce the depleting effect of suppressing stereotypes. Personality and Social Psychology Bulletin, 33, 281-294. doi:10.1177/0146167206296101

Gale, A. (1987). The psychophysiological context. In A. Gale and B. Christie (Eds.), Psychophysiology and the electronic workplace (pp. 17-32). Chichester, UK: Wiley. 
Gallagher, P., Fleeson, W., \& Hoyle, R. H. (2011). A self-regulatory mechanism for personality trait stability: Contra-trait effort. Social Psychological and Personality Science, 2, 335-342. doi:10.1177/1948550610390701

Glass, D. C., Singer, J. E., \& Friedman, L. N. (1969). Psychic cost of adaptation to an environmental stressor. Journal of Personality and Social Psychology, 12, 200-210. doi: $10.1037 / \mathrm{h} 0027629$

Goldberg, L. R. (1990). An alternative "description of personality": The big-five factor structure. Journal of Personality and Social Psychology, 59, 1217-1229. doi:10.1037/0022-3514.59.6.1216

Gray, J. A. (1991). The neurophysiology of temperament In J. Strelau \& A. Angleitner (Eds.), Explorations in temperament: International perspectives on theory and measurement (pp. 105-128). New York: Plenum.

Gray, J. A. (1972). The psychology of fear and stress. New York: McGraw-Hill.

Hagger, M. S., Wood, C., Stiff, C., \& Chatzisarantis, N. L. D. (2009). The strength model of selfregulation failure and health-related behavior. Health Psychology Review, 3, 208-238. doi:10.1080/17437190903414387

Hancock, P. A., \& Desmond, P. (Eds.). (2000). Stress workload and fatigue. Hillsdale, NJ: Lawrence Erlbaum.

Harley, T. A., \& Matthews, G. (1992). Interactive effects of extraversion, arousal and time of day on semantic priming: Are they pre-lexical or post-lexical? Personality and Individual Differences, 13, 1021-1029. doi:10.1016/0191-8869(92)90135-C

Herbener, E. S., Kagan, J., \& Cohen, M. (1989). Shyness and olfactory threshold. Personality and Individual Differences, 10, 1159-1163. doi:10.1016/0191-8869(89)90079-2 
Howarth, E. (1986). Introversion and neuroticism: A persistent relationship. Psychological Reports, 58, 389-390. doi:10.2466/pr0.1986.58.2.389.

John, O. P., \& Srivastava, S. (1999). The Big Five trait taxonomy: History, measurement, and theoretical perspectives. In L. A. Pervin \& O. P. John (Eds.), Handbook of personality: Theory and research (2nd ed., pp. 102-138). New York: Guilford.

Joireman, J., Balliet, D., Sprott, D., Spangenberg, E., \& Schultz, J. (2008). Consideration of future consequences, ego-depletion, and self-control: Support for distinguishing between CFC-Immediate and CFC-Future sub-scales. Personality and Individual Differences, 45, 15-21. doi:10.1016/j.paid.2008.02.011

Kagan, J. (1994). Galen's prophecy: Temperament in human nature. New York: Basic Books.

Kagan, J., \& Snidman, N. (2004). The Long Shadow of Temperament. Cambridge, MA: Harvard University Press.

Leith, K. P., \& Baumeister, R. F. (1996). Why do bad moods increase self-defeating behavior? Emotion, risk taking, and self-regulation. Journal of Personality and Social Psychology, 71, 1250-1267. doi:10.1037/0022-3514.71.6.1250

Levy, N. (2006). Addiction, autonomy and ego-depletion: A response to Bennett Foddy and Julian Savulescu. Bioethics, 20, 16-20. doi:10.1111/j.1467-8519.2006.00471.x

Liss, M., Mailloux, J., \& Erchull, M. J. (2008). The relationships between sensory processing sensitivity, alexithymia, autism, depression, and anxiety. Personality and Individual Differences, 45, 255-259. doi:10.1016/j.paid.2008.04.009.

Little, B. R. (2008). Personal projects and free traits: Personality and motivation reconsidered. Social and Personality Psychology Compass, 2/3, 1235-1254. doi:10.1111/j.17519004.2008.00106.x 
Logue, A. W. (1988). Research on self-control: An integrating framework. Behavioral and Brain Sciences, 11, 665-709. doi:10.1017/S0140525X00053978

Lorist, M. M., Boksem, M. A. S., \& Ridderinkhof, K. R. (2005). Impaired cognitive control and reduced cingulate activity during mental fatigue. Cognitive Brain Research, 24, 199 205. doi:10.1016/j.cogbrainres.2005.01.018

Matthews, G. \& Gilliland, K. (1999). The personality theories of H. J. Eysenck and J. A. Gray: A comparative view. Personality and Individual Differences, 26, 583-626. doi:10.1016/S0191-8869(99)00166-X

Metcalfe, J., \& Mischel, W. (1999). A hot/cool-system analysis of delay of gratification: The dynamics of willpower. Psychological Review, 106, 3-19. doi:10.1037/0033295X.106.1.3

Mischel,W., Shoda,Y., \& Peake, P. K. (1990). Predicting adolescent cognitive and selfregulatory competencies from preschool delay of gratification: Identifying diagnostic conditions. Developmental Psychology, 26, 978-986. doi:10.1037//0012-1649.26.6.978

Muraven, M., \& Baumeister, R. F. (2000). Self-regulation and depletion of limited resources: Does self-control resemble a muscle? Psychological Bulletin, 126, 247-259. doi: 10.1037//0033-2909.126.2.247

Muraven, M., Baumeister, R. F., \& Tice, D. M. (1999). Longitudinal improvement of selfregulation through practice: Building self-control strength through repeated exercise. Journal of Social Psychology, 139, 446-457. doi:10.1080/00224549909598404

Muraven, M., \& Slessareva, E. (2003). Mechanisms of self-control failure: Motivation and limited resources. Personality and Social Psychology Bulletin, 29, 894-906. doi:10.1177/0146167203253209 
Muraven, M., Tice, D. M., \& Baumeister, R. F. (1998). Self-control as a limited resource: Regulatory depletion patterns. Journal of Personality and Social Psychology, 74, 774 789. doi: $10.1037 / 0022-3514.74 .3 .774$

Myers, I. B. (1962). Manual for the Myers-Briggs Type Indicator. Princeton, NJ: Educational Testing Service.

Mayer, J. D., \& Gaschke, Y. N. (1988). The experience and metaexperience of mood. Journal of Personality and Social Psychology, 55, 102-111. doi:10.1037/0022-3514.55.1.102

Oaten, M., \& Cheng, K. (2006a). Improved self-control: The benefits of a regular program of academic study. Basic and Applied Social Psychology, 28, 1-16. doi:10.1207/s15324834basp2801__

Oaten, M., \& Cheng, K. (2006b). Longitudinal gains in self-regulation from regular physical exercise. British Journal of Health Psychology, 11, 717-733. doi:10.1348/135910706X96481

Oaten, M., \& Cheng, K. (2007). Improvements in self-control from financial monitoring. Journal of Economic Psychology, 28, 487-501. doi:10.1016/j.joep.2006.11.003

Patterson, CM., \& Newman, J. P. (1993). Reflectivity and learning from aversive events: Toward a psychological mechanism for the syndromes of disinhibition. Psychological Review, 100, 716-736. doi:10.1037/0033-295X.100.4.716

Richeson, J. A., \& Shelton, J. N. (2003). When prejudice does not pay: Effects of interracial contact on executive function. Psychological Science, 14, 287-290. doi:10.1111/1467-9280.03437

Richeson, J. A., Trawalter, S., \& Shelton, J. N. (2005). African Americans' implicit racial attitudes and the depletion of executive function after interracial interactions. Social 
Cognition, 23, 336-352. doi:10.1521/soco.2005.23.4.336

Rosenbaum, D.A., Carlson, R.A., \& Gilmore, R.O. (2001). Acquisition of intellectual and perceptual-motor skills. Annual Review of Psychology, 52, 453-470. doi:10.1146/annurev.psych.52.1.453

Ryan, R. M., \& Frederick, C. M. (1997). On energy, personality and health: Subjective vitality as a dynamic reflection of well-being. Journal of Personality, 65, 529-565. doi:10.1111/j.1467-6494.1997.tb00326.x

Schalling, D. (1971). Tolerance for experimentally induced pain as related to personality. Scandinavian Journal of Psychology, 12, 271-281. doi:10.1111/j.14679450.1971.tb00630.x

Schmeichel, B. J., \& Vohs, K. D. (2009). Self-affirmation and self-control: Affirming core values counteracts ego depletion. Journal of Personality and Social Psychology, 96, 770 782. doi: $10.1037 / \mathrm{a} 0014635$

Schouwenburg, H. C. (2004). Academic procrastination: Theoretical notions, measurement, and research. In H. C. Schouwenburg, C. H. Lay,T. A. Pychyl, \& J. R. Ferrari (Eds.), Counseling the procrastinator in academic settings (pp. 3-17). Washington, DC: American Psychological Association.

Seeley, E. A., \& Gardner, W. I. (2003). The "selfless" and self-regulation: The role of chronic other-orientation in averting self-regulatory depletion. Self and Identity, 2, 103-117. doi:10.1080/15298860309034

Segerstrom, S. C., \& Nes, L. S. (2007). Heart rate variability reflects self-regulatory strength, effort, and fatigue. Psychological Science, 18, 275-281. doi:10.1111/j.14679280.2007.01888.x 
Seligman, M. E. P. (1975). Helplessness: On depression, development, and death. San Francisco, CA: W. H. Freeman.

Siddle, D. A. T., Morrish, R. B., White, K. D., \& Mangan, G. L. (1969). Relation of visual sensitivity to extraversion. Journal of Experimental Research in Personality, 3, 264-267.

Shigehisa, T, (1974). Effect of auditory stimulation on visual tracking as functions of stimulus intensity, task complexity and personality. Japanese Psychological Research, 16, 186196.

Smolewska, K. A., McCabe, S. B., \& Woody, E. Z. (2006). A psychometric evaluation of the Highly Sensitive People scale: The components of sensory-processing sensitivity and their relation to the BIS/BAS and "Big Five". Personality and Individual Differences, 40 , 1269-1279. doi:10.1016/j.paid.2005.09.022.

Stelmack, R. M. (1990). Biological basis of extraversion: Psychophysiological evidence. Journal of Personality, 58, 293-311.

Stelmack, R. M., \& Campbell, K. B. (1974). Extraversion and auditory sensitivity to high and low frequency. Perceptual and Motor Skills, 38, 875-879.

doi:10.2466/pms.1974.38.3.875

Stelmack, R. M., \& Michaud-Achom, A. (1985). Extraversion, attention, and auditory evoked response. Journal of Research in Personality, 19, 416-428. doi:10.1016/0092$6566(85) 90009-1$

Stewart, C. C., Wright, R. A., Hui, S. K. A., \& Simmons, A. (2009). Outcome expectancy as a moderator of mental fatigue influence on cardiovascular response. Psychophysiology, 46, 1141-1149. doi:10.1111/j.1469-8986.2009.00862.x

Stroop, J. R. (1935). Studies of interference in serial verbal reactions. Journal of Experimental 
Psychology, 18, 643-661. doi:10.1037/h0054651

Tangney, J.P., Baumeister, R.F., \& Boone, A. (2004). High self-control predicts good adjustment, less pathology, better grades, and interpersonal success. Journal of Personality, 72, 271-324. doi:10.1111/j.0022-3506.2004.00263.x

Tice, D. M., Bratslavsky, E., \& Baumeister, R. F. (2001). Emotional distress regulation takes precedence over impulse control: If you feel bad, do it! Journal of Personality and Social Psychology, 80, 53-67. doi:10.1037/0022-3514.80.1.53

Tops, M., Lorist, M. M., Wijers, A. A., \& Meijman, T. F. (2004). To stress or relax: Neurochemical aspects of activity and rest. Gedrag en Organisatie, 17, 32-42. doi:10.1016/j.biopsycho.2005.08.007

Tyler, J. M. (2008). In the eyes of others: Monitoring for relational value cues. Human Communication Research, 34, 521-534. doi:10.1111/j.1468-2958.2008.00331.x

Tyler, J. M., \& Burns, K. C. (2009). Triggering conservation of the self's regulatory resources. Basic and Applied Social Psychology, 31, 255-266. doi:10.1080/01973530903058490

Van Den Berg, C. J. (1985). On the relation between energy transformations in the brain and mental activities. In G. R. J. Hockey, A. W. K. Gaillard, \& M. H. G. Coles (Eds.), Energetics and human information processing (pp.131-138). Dordrecht: Martinus Nijhoff Publishing.

Vohs, K. D., Baumeister, R. F., \& Ciarocco, N. J. (2005). Self-regulation and self-presentation: Regulatory resource depletion impairs impression management and effortful selfpresentation depletes regulatory resources. Journal of Personality and Social Psychology, 88, 632-657. doi:10.1037/0022-3514.88.4.632

Vohs, K. D., Baumeister, R. F., Schmeichel, B. J., Twenge, J. M., Nelson, N. M., \& Tice, D. M. 
(2008). Making choices impairs subsequent self-control: A limited-resource account of decision making, selfregulation, and active initiative. Journal of Personality and Social Psychology, 94, 883-898. doi:10.1037/0022-3514.94.5.883

Vohs, K. D., \& Faber, R. J. (2007). Spent resources: Self-regulatory resource availability affects impulse buying. Journal of Consumer Research, 33, 537-547. doi:10.1086/510228

Vohs, K. D., \& Heatherton, T. F. (2000). Self-regulatory failure: A resource-depletion approach. Psychological Science, 11, 249-254. doi:10.1111/1467-9280.00250

Wallace, H. M., \& Baumeister, R. F. (2002). The effects of success versus failure feedback on self-control. Self and Identity, 1, 35-42. doi:10.1080/152988602317232786

Watson, D., Clark, L. A., \& Tellegen, A. (1988). Development and validation of brief measures of positive and negative affect: The PANAS scales. Journal of Personality and Social Psychology, 54, 1063-1070. doi:10.1037/0022-3514.54.6.1063

Wen Wan, E., \& Sternthal, B. (2008). Regulating the effects of depletion through monitoring. Personality and Social Psychology Bulletin, 34, 32-46. doi: $10.1177 / 0146167207306756$

Wills, T. A., \& Dishion, T. J. (2004). Temperament and adolescent substance use: A transactional analysis of emerging self-control. Journal of Clinical Child and Adolescent Psychology, 33, 69-81. doi:10.1207/S15374424JCCP3301_7

Wills, T.A., \& Stoolmiller, M. (2002). The role of self-control in early escalation of substance use. Journal of Consulting and Clinical Psychology, 70, 986-997. doi: 10.1037/0022006X.70.4.986

Wright, R. A., Martin, R. E., \& Bland, J. L. (2003). Energy resource depletion, task difficulty, and cardiovascular response to a mental arithmetic challenge. Psychophysiology, 40, 98- 
105. doi:10.1111/1469-8986.00010 


\section{Appendix A - Tables}

Table 1

Sample Demographics

\begin{tabular}{cc}
\hline Variable & $\mathrm{n}(\%)$ \\
\hline Year of study: & \\
\hline $1^{\text {st }}$ & $61(51.70)$ \\
$2^{\text {nd }}$ & $37(31.40)$ \\
$3^{\text {rd }}$ & $14(11.90)$ \\
$4^{\text {th }}$ & $5(4.20)$ \\
Masters & $1(0.80)$ \\
& \\
Race: & \\
Caucasian & $60(50.80)$ \\
Asian/Pacific Islander & $18(15.30)$ \\
Black & $17(14.40)$ \\
Arab & $9(7.60)$ \\
Multiracial & $7(5.90)$ \\
Would rather not say & $4(3.40)$ \\
Indigenous or Aboriginal & $2(1.70)$ \\
Hispanic & $1(0.80)$
\end{tabular}

Primary language:

$\begin{array}{lc}\text { English } & 86(72.90) \\ \text { Other } & 14(11.90) \\ \text { Chinese } & 10(8.50) \\ \text { Arabic } & 6(5.10) \\ \text { French } & 2(1.70)\end{array}$

Within "Other" primary language:

$\begin{array}{lc}\text { Urdu } & 3(2.50) \\ \text { Dari } & 2(1.70) \\ \text { Somali } & 1(0.80) \\ \text { Farsi } & 1(0.80) \\ \text { Bulgarian } & 1(0.80) \\ \text { English/Arabic } & 1(0.80) \\ \text { Gujarati } & 1(0.80) \\ \text { Hebrew } & 1(0.80) \\ \text { Malay } & 1(0.80) \\ \text { Russian } & 1(0.80) \\ \text { Swahili } & 1(0.80)\end{array}$


Table 2

Descriptive Statistics for Measures Used in the Study

\begin{tabular}{|c|c|c|c|c|}
\hline Variable & $\mathrm{N}$ & Mean & SD & Range \\
\hline HSP & 118 & 107.23 & 18.65 & $67-162$ \\
\hline HSP - Ease of Excitation & 118 & 51.01 & 10.98 & $21-78$ \\
\hline HSP - Aesthetic Sensitivity & 118 & 31.36 & 5.16 & $16-43$ \\
\hline HSP - Low Sensory Threshold & 118 & 18.43 & 6.54 & $6-36$ \\
\hline $\mathrm{BFI}$ - Extraversion & 118 & 26.93 & 5.73 & $10-39$ \\
\hline BFI - Agreeableness & 118 & 31.21 & 5.43 & $15-40$ \\
\hline BFI - Consciousness & 118 & 31.54 & 5.44 & $19-44$ \\
\hline BFI - Neuroticism & 118 & 22.47 & 6.13 & $8-38$ \\
\hline BFI - Openness & 118 & 35.20 & 5.26 & $21-45$ \\
\hline EPQ - Extraversion & 118 & 27.39 & 4.29 & $21-41$ \\
\hline EPQ - Neuroticism & 118 & 36.13 & 5.29 & $24-44$ \\
\hline BAS & 118 & 41.91 & 5.30 & $25-52$ \\
\hline BAS - Drive & 118 & 11.25 & 2.55 & $6-16$ \\
\hline BAS - Fun Seeking & 118 & 12.68 & 2.24 & $6-16$ \\
\hline BAS - Reward Responsiveness & 118 & 17.98 & 1.99 & $12-20$ \\
\hline BIS & 118 & 20.34 & 3.94 & $9-29$ \\
\hline SVS & 118 & 25.75 & 6.55 & $6-39$ \\
\hline PANAS - Positive Affect & 118 & 28.65 & 8.49 & $10-48$ \\
\hline
\end{tabular}


Table 2 (continued)

Descriptive Statistics for Measures Used in the Study: Continuation

\begin{tabular}{lcccc}
\hline Variable & $\mathrm{N}$ & Mean & SD & Range \\
\hline PANAS - Negative Affect & 118 & 14.79 & 4.81 & $9-30$ \\
Effort & 118 & 10.74 & 3.07 & $4-19$ \\
Stroop task (trimmed in secs) & & & & \\
\multicolumn{1}{c}{ Mean RT of incongr. corr. } & 118 & 887.11 & 135.86 & $600.99-1259.60$ \\
$\quad$ Number of incongr. corr. & 118 & 252.02 & 7.15 & $199-260$ \\
$\quad$ Median RT of correct & 118 & 810.77 & 107.56 & $573.50-1109.00$ \\
$\quad$ Interference of correct & 118 & 52.40 & 48.12 & $-46.18-215.11$ \\
Text A time (in mins) & 118 & 7.62 & 1.64 & $3.40-10.00$ \\
Text B time (in mins) & 118 & 9.05 & 1.31 & $3.51-10.00$ \\
Text A completed lines & 118 & 31.62 & 2.00 & $21.75-33.00$ \\
Text B completed lines & 118 & 8.74 & 5.65 & $10.00-34.00$ \\
Text A number of mistakes & 118 & 34.34 & 21.54 & $6-124$ \\
Text B number of mistakes & 118 & 46.29 & 34.00 & $6-163$
\end{tabular}

Note 1: HSP = The Highly Sensitive Person Scale, BFI = The Big Five Inventory, EPQ = Eysenck's Personality Questionnaire, BIS/BAS $=$ The Behavioral Inhibition and Behavioral Activation Scale, SVS = The Subjective Vitality Scale, PANAS = The Positive and Negative Affect Schedule, Effort $=$ The Effort Scale.

Note 2: All of the Stroop task answers, which exceeded response time of 3000 or were less than response time of 300 were excluded from the analysis; RT $=$ response time.

Note 3: Text A and Text B times = time participants took to cross out all the " $\mathrm{e}$ " letters; Text A and Text $\mathrm{B}$ completed lines = number of lines of text participants have worked on. 


\section{Appendix B - Demographic Information}

Sex: Female/ Male (please circle one)

Age:

How would you classify yourself?

Arab

_ Asian/Pacific Islander

_ Black

_ Caucasian/White

_. Hispanic

_ Indigenous or Aboriginal

_ Latino

_ Multiracial

_ Would rather not say

What is your primary language?

_ English

- French

_ Spanish

Arabic

_ Aboriginal

Chinese languages

_. Punjabi

Other: (please write)

What is your current year of study at Carleton University?

$$
\begin{array}{ll}
1^{\text {st }} \text { year (undergraduate) } & 2^{\text {nd }} \text { year (undergraduate) } \\
3^{\text {rd }} \text { year (undergraduate) } & -\begin{array}{l}
4^{\text {th }} \text { year (undergraduate) } \\
\text { master's }
\end{array} \quad \text { doctoral }
\end{array}
$$




\section{Appendix C - BIS/BAS}

Each item of this questionnaire is a statement that a person may either agree with or disagree with. For each item, indicate how much you agree or disagree with what the item says. Please respond to all the items; do not leave any blank. Choose only one response to each statement. Please be as accurate and honest as you can be. Respond to each item as if it were the only item. That is, don't worry about being "consistent" in your responses. Choose from the following four response options:

\begin{tabular}{|c|c|c|c|}
\hline Very true for me & Somewhat true for me & Somewhat false for me & Very false for me \\
\hline
\end{tabular}

1. A person's family is the most important thing in life.

2. Even if something bad is about to happen to me, I rarely experience fear or nervousness.

3. I go out of my way to get things I want.

4. When I'm doing well at something I love to keep at it.

5. I'm always willing to try something new if I think it will be fun.

6. How I dress is important to me.

7. When I get something I want, I feel excited and energized.

8. Criticism or scolding hurts me quite a bit.

9. When I want something I usually go all-out to get it.

10. I will often do things for no other reason than that they might be fun.

11. It's hard for me to find the time to do things such as get a haircut.

12. If I see a chance to get something I want I move on it right away.

13. I feel pretty worried or upset when I think or know somebody is angry at me.

14. When I see an opportunity for something I like I get excited right away.

15. I often act on the spur of the moment.

16. If I think something unpleasant is going to happen I usually get pretty "worked up."

17. I often wonder why people act the way they do.

18. When good things happen to me, it affects me strongly.

19. I feel worried when I think I have done poorly at something important.

20. I crave excitement and new sensations.

21. When I go after something I use a "no holds barred" approach.

22. I have very few fears compared to my friends.

23. It would excite me to win a contest.

24. I worry about making mistakes. 


\section{Appendix D - Eysenck's Personality Questionnaire}

\section{FOR EVERY QUESTION, CIRCLE JUST ONE RESPONSE}

YES NO 1. Do you have many different hobbies?

YES NO 2. Does your mood often go up and down?

YES NO 3. Are you a talkative person?

YES NO 4. Do you feel "just miserable" for no reason?

YES NO 5. Are you rather lively?

YES NO 6. Do you often worry about things you should not have done or said?

YES NO 7. Can you usually let yourself go and enjoy yourself at a lively party?

YES NO 8. Are you an irritable person?

YES NO 9. Do you enjoy meeting new people?

YES NO 10. Are your feelings easily hurt?

YES NO 11. Do you tend to keep in the background on social occasions?

YES NO 12. Do you often feel "fed-up?"

YES NO 13. Do you like going out a lot?

YES NO 14. Are you often troubled about feelings of guilt?

YES NO 15. Do you prefer reading to meeting people?

YES NO 16. Would you call yourself a nervous person?

YES NO 17. Do you have many friends?

YES NO 18. Are you a worrier?

YES NO 19. Would you call yourself happy-go-lucky?

YES NO 20. Do you worry about awful things that might happen?

YES NO 21. Do you usually take the initiative in making new friends?

YES NO 22. Would you call yourself tense or "highly-strung"?

YES NO 23. Are you mostly quiet when you are with other people?

YES NO 24. Can you easily get some life into a rather dull party?

YES NO 25. Do you worry about your health?

YES NO 26. Do you like telling jokes and funny stories to your friends?

YES NO 27. Do you like mixing with people?

YES NO 28. Do you suffer from sleeplessness?

YES NO 29. Do you nearly always have a "ready answer" when people talk to you?

YES NO 30. Have you often felt listless and tired for no reason?

YES NO 31. Do you like doing things in which you have to act quickly?

YES NO 32. Do you often feel life is very dull? 
YES NO 33. Do you often take on more activities than you have time for?

YES NO 34. Do you worry a lot about your looks?

YES NO 35. Have you ever wished that you were dead?

YES NO 36. Can you get a party going?

YES NO 37. Do you worry too long after an embarrassing experience?

YES NO 38. Do you suffer from "nerves"?

YES NO 39. Do you often feel lonely?

YES NO 40. Are you easily hurt when people find fault with you or the work you do?

YES NO 41. Do you like plenty of bustle and excitement around you?

YES NO 42. Are you sometimes bubbling over with energy and sometimes very sluggish?

YES NO 43. Do other people think of you as very lively?

YES NO 44. Are you touchy about some things? 


\section{Appendix E - The Big Five Inventory (BFI)}

Here are a number of characteristics that may or may not apply to you. For example, do you agree that you are someone who likes to spend time with others? Please write a number next to each statement to indicate the extent to which you agree or disagree with that statement.

$\begin{array}{lcccc}\text { Disagree } & \text { Disagree } & \text { Neither Agree nor } & \text { Agree } & \text { Agree } \\ \text { strongly } & \text { a little } & \text { disagree } & \text { a little } & \text { strongly } \\ 1 & 2 & 3 & 4 & 5\end{array}$

\section{I see Myself as Someone Who...}

1. Is talkative

2. Tends to find fault with others

3. Does a thorough job

4. Is depressed, blue

5. Is original, comes up with new ideas

6. Is reserved

7. Is helpful and unselfish with others

8. Can be somewhat careless

9. Is relaxed, handles stress well

10. Is curious about many different things

11. Is full of energy

12. Starts quarrels with others

13. Is a reliable worker

14. Can be tense

15. Is ingenious, a deep thinker

16. Generates a lot of enthusiasm

17. Has a forgiving nature

18. Tends to be disorganized

19. Worries a lot

20. Has an active imagination

21. Tends to be quiet

22. Is generally trusting
23. Tends to be lazy

24. Is emotionally stable, not easily upset

25. Is inventive

26. Has an assertive personality

27. Can be cold and aloof

28. Perseveres until the task is finished

29. Can be moody

30. Values artistic, aesthetic experiences

31. Is sometimes shy, inhibited

32. Is considerate and kind to almost everyone

33. Does things efficiently

34. Remains calm in tense situations

35. Prefers work that is routine

36. Is outgoing, sociable

37. Is sometimes rude to others

38. Makes plans and follows through with them

39. Gets nervous easily

40. Likes to reflect, play with ideas

41. Has few artistic interests

42. Likes to cooperate with others

43. Is easily distracted

44. Is sophisticated in art, music, or literature 


\section{Appendix F - HSP Scale}

1. Are you easily overwhelmed by strong sensory input?
1
2
3
4
5
6
7
not at all

2. Do you seem to be aware of subtleties in your environment?

$\begin{array}{ccccccc}1 & 2 & 3 & 4 & 5 & 6 & 7 \\ \text { not at all } & & & & & \text { extremely }\end{array}$

3. Do other people's moods affect you?

$\begin{array}{ccccccc}1 & 2 & 3 & 4 & 5 & 6 & 7 \\ \text { not at all } & & & & & \text { extremely }\end{array}$

4. Do you tend to be more sensitive to pain?

$\begin{array}{ccccccc}1 & 2 & 3 & 4 & 5 & 6 & 7 \\ \text { not at all } & & & & & \text { extremely }\end{array}$

5. Do you find yourself needing to withdraw during busy days into bed or into a darkened room or any place where you can have some privacy and relief from stimulation?

$\begin{array}{ccccccc}1 & 2 & 3 & 4 & 5 & 6 & 7 \\ \text { not at all } & & & & & \text { extremely }\end{array}$

6. Are you particularly sensitive to the effects of caffeine?

$\begin{array}{ccccccc}1 & 2 & 3 & 4 & 5 & 6 & 7 \\ \text { not at all } & & & & & & \text { extremely }\end{array}$

7. Are you easily overwhelmed by things like bright lights, strong smells, coarse fabrics, or sirens close by?

$\begin{array}{ccccccc}1 & 2 & 3 & 4 & 5 & 6 & 7 \\ \text { not at all } & & & & \text { extremely }\end{array}$

8. Do you have a rich, complex inner life?

$\begin{array}{lllllll}1 & 2 & 3 & 4 & 5 & 6 & 7 \\ \text { extremely }\end{array}$


17. Do you try hard to avoid making mistakes or forgetting things?
1
not at all
$2 \quad 3$
4
5
6
7
extremely

18. Do you make a point to avoid violent movies and TV shows?

$\begin{array}{ccccccc}1 & 2 & 3 & 4 & 5 & 6 & \begin{array}{c}7 \\ \text { not at all }\end{array} \\ & & & & & & \text { extremely }\end{array}$

19. Do you become unpleasantly aroused when a lot is going on around you?

$\begin{array}{ccccccc}1 & 2 & 3 & 4 & 5 & 6 & 7 \\ \text { not at all } & & & & & & \text { extremely }\end{array}$

20. Does being very hungry create a strong reaction in you, disrupting your concentration or mood?

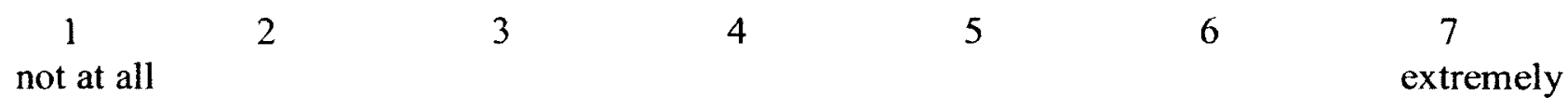

21. Do changes in your life shake you up?

$\begin{array}{ccccccc}1 & 2 & 3 & 4 & 5 & 6 & 7 \\ \text { not at all } & & & & & & \end{array}$

22. Do you notice and enjoy delicate or fine scents, tastes, sounds, works of art?

$\begin{array}{ccccccc}1 & 2 & 3 & 4 & 5 & 6 & 7 \\ \text { not at all } & & & & & & \end{array}$

23. Do you find it unpleasant to have a lot going on at once?

$\begin{array}{ccccccc}1 & 2 & 3 & 4 & 5 & 6 & 7 \\ \text { not at all } & & & & & & \end{array}$

24. Do you make it a high priority to arrange your life to avoid upsetting or overwhelming situations?
1
not at all
23
4
5
6
7 extremely

25. Are you bothered by intense stimuli, like loud noises or chaotic scenes?

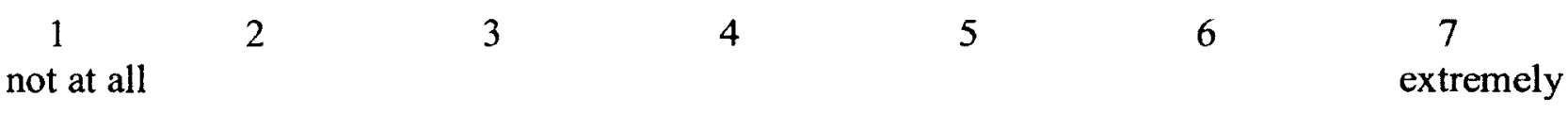


26. When you must compete or be observed while performing a task, do you become so nervous or shaky that you do much worse than you would otherwise?

$\begin{array}{ccccccc}1 & 2 & 3 & 4 & 5 & 6 & 7 \\ \text { not at all } & & & & & \text { extremely }\end{array}$

27. When you were a child, did parents or teachers seem to see you as sensitive or shy?

$\begin{array}{lllllll}1 & 2 & 3 & 4 & 5 & 6 & 7\end{array}$

not at all

7 extremely 


\section{Appendix G - Texts}

\section{Text A}

Instructions: Read the following passage and highlight every letter " $\mathrm{e}$ " that you see. Please be as quick and accurate as possible. You will not be timed on this task.

The purpose of mechanics is to describe how bodies change their position in space with time." I should load my conscience with grave sins against the sacred spirit of lucidity were I to formulate the aims of mechanics in this way, without serious reflection and detailed explanations. Let us proceed to disclose these sins.

It is not clear what is to be understood here by "position" and "space." I stand at the window of a railway carriage which is traveling uniformly, and drop a stone on the embankment, without throwing it. Then, disregarding the influence of the air resistance, I see the stone descend in a straight line. A pedestrian who observes the misdeed from the footpath notices that the stone falls to earth in a parabolic curve. I now ask: Do the "positions" traversed by the stone lie "in reality" on a straight line or on a parabola? Moreover, what is meant here by motion "in space"? From the considerations of the previous section the answer is self-evident. In the first place, we entirely shun the vague word "space," of which, we must honestly acknowledge, we cannot form the slightest conception, and we replace it by "motion relative to a practically rigid body of reference." The positions relative to the body of reference (railway carriage or embankment) have already been defined in detail in the preceding section. If instead of "body of reference" we insert "system of co-ordinates," which is a useful idea for mathematical description, we are in a position to say: The stone traverses a straight line relative to a system of co-ordinates rigidly attached to the carriage, but relative to a system of co-ordinates rigidly attached to the ground (embankment) it describes a parabola. With the aid of this example it is clearly seen that there is no such thing as an independently existing trajectory (lit. "path-curve") ${ }^{8}$, but only a trajectory relative to a particular body of reference.

In order to have a complete description of the motion, we must specify how the body alters its position with time; i.e. for every point on the trajectory it must be stated at what time the body is situated there. These data must be supplemented by such a definition of time that, in virtue of this definition, these time-values can be regarded essentially as magnitudes (results of measurements) capable of observation. If we take our stand on the ground of classical mechanics, we can satisfy this requirement for our illustration in the following manner. We imagine two clocks of identical construction; the man at the railway-carriage window is holding one of them, and the man on the footpath the other. Each of the observers determines the position on his own reference-body occupied by the stone at each tick of the clock he is holding in his hand. In this connection we have not taken account of the inaccuracy involved by the finiteness of the velocity of propagation of light.

8. That is, a curve along which the body moves. 


\section{Text B}

Instructions: Read the following passage and highlight every letter "e" that you see, except when it is either next to a vowel or if there was a vowel two letters removed. (e.g., you would NOT highlight either the letter Es in the words "real" or "evaluate"). Please be as quick and accurate as possible. You will not be timed on this task.

In order to attain the greatest possible clearness, let us return to our example of the railway carriage supposed to be traveling uniformly. We call its motion a uniform translation ("uniform" because it is of constant velocity and direction, "translation" because although the carriage changes its position relative to the embankment yet it does not rotate in so doing). Let us imagine a raven flying through the air in such a manner that its motion, as observed from the embankment, is uniform and in a straight line. If we were to observe the flying raven from the moving railway carriage, we should find that the motion of the raven would be one of different velocity and direction, but that it would still be uniform and in a straight line. Expressed in an abstract manner we may say: If a mass $m$ is moving uniformly in a straight line with respect to a co-ordinate system $\mathrm{K}$, then it will also be moving uniformly and in a straight line relative to a second co-ordinate system $\mathrm{K}^{\prime}$, provided that the latter is executing a uniform translatory motion with respect to $\mathrm{K}$. In accordance with the discussion contained in the preceding section, it follows that:

If $\mathrm{K}$ is a Galileian co-ordinate system, then every other co-ordinate system $\mathrm{K}^{\prime}$ is a Galileian one, when, in relation to $\mathrm{K}$, it is in a condition of uniform motion of translation. Relative to $\mathrm{K}^{\prime}$ the mechanical laws of Galilei-Newton hold good exactly as they do with respect to $\mathrm{K}$. We advance a step farther in our generalization when we express the tenet thus: If, relative to $\mathrm{K}, \mathrm{K}$ ' is a uniformly moving co-ordinate system devoid of rotation, then natural phenomena run their course with respect to $\mathrm{K}^{\prime}$ according to exactly the same general laws as with respect to $\mathrm{K}$. This statement is called the principle of relativity (in the restricted sense).

As long as one was convinced that all natural phenomena were capable of representation with the help of classical mechanics, there was no need to doubt the validity of this principle of relativity. But in view of the more recent development of electrodynamics and optics it became more and more evident that classical mechanics affords an insufficient foundation for the physical description of all natural phenomena. At this juncture the question of the validity of the principle of relativity became ripe for discussion, and it did not appear impossible that the answer to this question might be in the negative.

Nevertheless, there are two general facts which at the outset speak very much in favour of the validity of the principle of relativity. Even though classical mechanics does not supply us with a sufficiently broad basis for the theoretical presentation of all physical phenomena, still we must grant it a considerable measure of "truth," since it supplies us with the actual motions of the heavenly bodies with a delicacy of detail little short of wonderful. The principle of relativity must therefore apply with great accuracy in the domain of mechanics. 


\section{Appendix H - PANAS}

This scale consists of a number of words that describe different feelings and emotions. Read each item and then mark the appropriate answer in the space next to that word. Indicate to what extent you feel this way right now, at this moment. Use the following scale to record your answers:

12

very slightly

a little

or not at all

Attentive

Strong

Irritable

Inspired

Afraid

Alert

Upset

Active

Guilty

Nervous
3

4

5

moderately

extremely 


\section{Appendix I - Subjective Vitality Scale}

Please respond to each of the following statements by indicating the degree to which the statement is true for you in general in your life. Use the following scale:

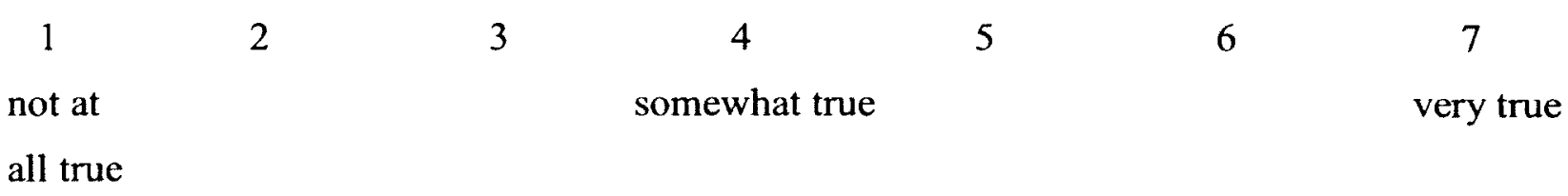

1. I feel alive and vital.

2. Sometimes I feel so alive I just want to burst.

3. I have energy and spirit.

4. Ilook forward to each new day.

5. I nearly always feel alert and awake.

6. I feel energized. 


\section{Appendix J - Effort Scale}

Please answer each question below by writing the appropriate number in the box next to each question. Use the following scale:

$\begin{array}{lllll}2 & 2 & 3 & 4 & 5\end{array}$

$\begin{aligned} & \text { very slightly a little } \quad \text { moderately } \\ & \text { or not at all }\end{aligned}$

Your answers:

\begin{tabular}{|l|l|}
\hline & How effortful was it to act according to the instructions you were given? \\
\hline & How tired or fatigued did acting the way you did make you? \\
\hline & How easy was it to follow the instructions you were given to behave the way you did? \\
\hline & How much effort did it take to act the way you did? \\
\hline
\end{tabular}

